\title{
Lanthanum Zirconate Based Thermal Barrier Coatings: A Review
}

\author{
Jing Zhang ${ }^{\mathrm{a}, *}$, Xingye Guo ${ }^{\mathrm{a}}$, Yeon-Gil Jung ${ }^{\mathrm{b}}, \mathrm{Li} \mathrm{Li}^{\mathrm{c}}$, James Knapp ${ }^{\mathrm{c}}$ \\ a Department of Mechanical Engineering, Indiana University-Purdue University \\ Indianapolis, Indianapolis, IN 46202, USA \\ b School of Materials Science and Engineering, Changwon National University, Changwon, \\ Gyeongnam 641-773, Republic of Korea \\ c Praxair Surface Technologies Inc., Indianapolis, IN 46222, USA \\ *Corresponding author: jz29@iupui.edu
}

\begin{abstract}
This review article summarizes the latest information about the manufacturing techniques of lanthanum zirconate $\left(\mathrm{La}_{2} \mathrm{Zr}_{2} \mathrm{O}_{7}, \mathrm{LZ}\right)$ powder and $\mathrm{La}_{2} \mathrm{Zr}_{2} \mathrm{O}_{7}$ based thermal barrier coatings (TBCs). Lanthanum zirconate is a promising candidate material for TBC applications, due to its lower thermal conductivity and higher thermal stability compared to other traditional TBC systems. In this work, the physical, thermal, and mechanical properties of the powder and coatings are evaluated. The durability experiments of the TBCs in various thermal, mechanical, and corrosive conditions is also reviewed. In addition, theoretical studies on the powder and coatings properties are presented. Finally, future research directions of lanthanum zirconate as TBC applications are proposed.
\end{abstract}

Keywords: Lanthanum zirconate; Thermal barrier coating; Properties; Durability; Modeling

This is the author's manuscript of the article published in final edited form as:

Zhang, J., Guo, X., Jung, Y.-G., Li, L., \& Knapp, J. (2016). Lanthanum zirconate based thermal barrier coatings: A review. Surface and Coatings Technology. https://doi.org/10.1016/j.surfcoat.2016.10.019 


\section{Introduction}

Thermal barrier coatings are multi-layer coating systems deposited on turbine components, especially turbine blade, which thermally insulate and protect them against hot and corrosive gas streams [1-3]. Typical structure of TBCs includes four layers: (1) superalloy substrate; (2) bond coat; (3) thermally grown oxide (TGO); and (4) ceramic top coat. The bond coat consists of a MCrAlM' intermetallic alloy with a thickness of $100 \sim 300 \mu \mathrm{m}$, wherein $\mathrm{M}$ is an element selected from nickel, cobalt, iron and their mixture, and $\mathrm{M}^{\prime}$ 'is an element selected from yttrium, zirconium, hafnium, ytterbium and mixture thereof [4]. Typically, TBCs can be deposited directly on the substrate using various techniques, such as air plasma spraying (APS), electron-beam physical vapor deposition (EB-PVD), high velocity oxygen-fuel (HVOF) spraying, vacuum plasma spraying, low-pressure plasma spraying and diffusion bond method [5-8]. In high-temperature operation conditions, a TGO layer is formed at the interface between the bond and top coats with a thickness of $1 \sim 10 \mu \mathrm{m}$. The main composition of TGO is $\alpha$-alumina $\left(\alpha-\mathrm{Al}_{2} \mathrm{O}_{3}\right)$, which functions as a good oxygen diffusion barrier. The ceramic top coat is one or multiple low thermal conductivity ceramic layers with a typical thickness of $100 \sim 600 \mu \mathrm{m}$, which is deposited by APS or EB-PVD methods [3, 9]. The criteria for selecting TBC materials include high melting point, low thermal conductivity, high coefficient of thermal expansion (CTE), good thermal and chemical stability, no phase change, low sintering activity, good erosion resistance, and good foreign objective damage (FOD) or calcium-magnesium-alumino-silicate (CMAS) resistance [10].

Currently, the state-of-the-art TBCs are 7 8 wt \% yttria stabilized zirconia (8YSZ). 8YSZ has a metastable tetragonal phase $\left(t^{\prime}\right)$, and $\mathrm{Y}_{2} \mathrm{O}_{3}$ is used to stabilize the $\mathrm{ZrO}_{2}$ structure. $8 \mathrm{YSZ}$ has a relatively high melting point $\left(2680^{\circ} \mathrm{C}\right)[10]$, relatively low thermal conductivity ( 2.0 $2.3 \mathrm{~W} / \mathrm{m} / \mathrm{K}$ at $\sim 1000{ }^{\circ} \mathrm{C}$ for a fully dense; $0.9-1.2 \mathrm{~W} / \mathrm{m} / \mathrm{K}$ for $10-15 \%$ porosity) [11, 12], a relatively high CTE $\left(11 \times 10^{-6} / \mathrm{K}\right.$ at $\left.\sim 1000{ }^{\circ} \mathrm{C}\right)$ [10], and good thermal and chemical stability [13]. However, the maximum surface temperature that can be employed for $8 \mathrm{YSZ}$ based TBCs is limited to $1200{ }^{\circ} \mathrm{C}$ for long term operations. At temperatures above $1200{ }^{\circ} \mathrm{C}$, there are two important degradation mechanisms in 8YSZ. The first mechanism is that the $t^{\prime}$ phase of YSZ will decompose into two equilibrium tetragonal $(t)$ and cubic $(c)$ phases. During cooling process, the $t$ phase will transform to the monoclinic $(m)$ phase, accompanied with $\sim 4 \%$ volume expansion. The other mechanism is the sintering of coating, which will densify 
the microstructure, and thus increase the thermal conductivity. The phase and microstructure changes as well as property changes will finally lead to high thermal induced stress and reduced coating's lifetime [10] [14]. Therefore, there is continued effort searching for alternative TBC materials that meet the needs of next-generation advanced gas turbines.

Lanthanum zirconate $\left(\mathrm{La}_{2} \mathrm{Zr}_{2} \mathrm{O}_{7}, \mathrm{LZ}\right)$ is a typical pyrochlore structure ceramic material. The general chemical formula of the pyrochlore structure is $\mathrm{A}_{2} \mathrm{~B}_{2} \mathrm{O}_{7}$. A element in $\mathrm{A}_{2} \mathrm{~B}_{2} \mathrm{O}_{7}$ generally is a rare earth or an element with an inert single pair of electrons, and $\mathrm{B}$ element typically is a transition metal or a post-transition metal with a variable oxidation state $[5,15]$. Compared to 8YSZ, LZ has many advantages for TBC applications: (1) no phase transformation from room temperature to its melting temperature; (2) considerably high sintering resistance; (3) a very low thermal conductivity $\left(1.5-1.8 \mathrm{~W} / \mathrm{m} / \mathrm{K}\right.$ at $1000{ }^{\circ} \mathrm{C}$ for a fully dense material); and (4) LZ has a lower oxygen ion diffusivity, which protects the bond coat and the substrate from oxidation [10]. The principle drawback of LZ is its low CTE value, which does not match the high CTE values of bond coat and substrate.

The objective of this paper is to provide a comprehensive review of the manufacturing techniques of LZ powder and LZ based thermal barrier coatings, with a focus of comparing LZ with 8YSZ, the current state of the art thermal barrier coating material. The paper is arranged as follows. Chapter 2 provides the information of fabrication technique and characterization of LZ powder. Chapter 3 presents the fabrication methods of LZ based TBCs. Chapter 4 summarizes the physical properties of LZ based TBCs. Chapter 5 shows coatings' thermal properties. Chapter 6 presents coatings' mechanical properties. Chapter 7 provides the durability analyses, including thermal cycling test, erosion test, hot corrosion, and CMAS infiltration damage test. Chapter 8 presents modeling and simulation studies. Chapter 9 provides concluding remarks on future research directions.

\section{Fabrication and characterization of lanthanum zirconate powder}

\subsection{Powder fabrication}

There are several fabrication methods for LZ powder, including solid state reaction method, co-precipitation method and sol-gel method, etc. [10, 16-18]. For thermal spray applications, 
LZ powder can be synthesized by the solid state reaction method from a mixture of the lanthanum oxide $\left(\mathrm{La}_{2} \mathrm{O}_{3}, 99.9 \%\right)$ and $\mathrm{ZrO}_{2}(99 \%)$ powders at high temperatures $(1773 \mathrm{~K})$ under an argon atmosphere for $10 \mathrm{hrs}[16,17]$. The pure $\mathrm{La}_{2} \mathrm{O}_{3}$ is typically prepared by dissolving $\mathrm{La}_{2}\left(\mathrm{CO}_{3}\right)_{3} \cdot 8 \mathrm{H}_{2} \mathrm{O}$ in nitric acid and subsequently producing a precipitate by addition of $\mathrm{NH}_{3}$. The precipitate is dried in air and then heated in oxygen at $1173 \mathrm{~K}$ to remove the nitrogen-containing fragments. The resulting $\mathrm{La}_{2} \mathrm{O}_{3}$ is heated at $1473 \mathrm{~K}$ to remove any absorbed water [16]. The fabricated LZ powders are in spherical or ellipsoidal shape with a porous microstructure. The theoretical chemical composition of LZ powder is: La $48.6 \mathrm{wt} . \%$, $\mathrm{Zr} 31.9$ wt.\%, O 19.5 wt.\%, which is equivalent to $1: 2$ molar ratios of $\mathrm{La}_{2} \mathrm{O}_{3}$ to $\mathrm{ZrO}_{2}$ [13].

In the co-precipitation method, an aqueous solution of lanthanum nitrate hexahydrate $\left(\mathrm{La}\left(\mathrm{NO}_{3}\right)_{3} \cdot 6 \mathrm{H}_{2} \mathrm{O}\right)$ and zirconium oxychloride $\left(\mathrm{ZrOCl}_{2} \cdot 8 \mathrm{H}_{2} \mathrm{O}\right)$ with a diluted $\mathrm{NH}_{3}$ solution is used to prepare $\mathrm{LZ}$ powder [10]. During this preparation process, the $\mathrm{La}\left(\mathrm{NO}_{3}\right)_{3} \cdot 6 \mathrm{H}_{2} \mathrm{O}$ and $\mathrm{ZrOCl}_{2} \cdot 8 \mathrm{H}_{2} \mathrm{O}$ are dissolved in distilled water in equimolar amounts. The liquid mixtures are slowly added under stirring to an ammonium hydrate solution with $\mathrm{pH} 12.5$. The resulting precipitate is filtered, washed with distilled water, and then dried at $120^{\circ} \mathrm{C}$ overnight. The remaining solid is then calcined at $900^{\circ} \mathrm{C}$ for $5 \mathrm{hrs}$. The sol-gel method is another way to

synthesize nanostructured powders, which have high sintering ability for the $\mathrm{A}_{2} \mathrm{Zr}_{2} \mathrm{O}_{7}(\mathrm{~A}=\mathrm{La}$, $\mathrm{Nd}, \mathrm{Sm})$ system [18].

The manufacturing criteria of LZ feedstock powders are (1) spherical shape powder, (2) uniform and fine particle size, (3) homogeneous composition, (4) high purity, and (5) low fabrication cost. The requirements of the shape and size distribution are based on the fact that powder flowability is very important in thermal spray process. The spherical shaped powder and its uniform particle size are critical for smooth flow of powders through the feedstockfeeding pipe.

\subsection{Crystal structure}

$\mathrm{LZ}$ is a typical $\mathrm{ZrO}_{2}-\mathrm{Ln}_{2} \mathrm{O}_{3}(\mathrm{Ln}$ is lanthanide elements, $\mathrm{Ln}=\mathrm{La} \sim \mathrm{Gd})$ system, which has a pyrochlore structure with a space group $F d \overline{3} m$ [19]. Although the $\mathrm{Ln}_{2} \mathrm{Zr}_{2} \mathrm{O}_{7}(\mathrm{Ln}=\mathrm{La} \sim \mathrm{Gd})$ compounds are stable at room temperature, an order-disorder transition occurs at high temperatures $\left(>1500{ }^{\circ} \mathrm{C}\right)$, namely the compounds change from pyrochlore to defect fluorite 
structure, with the only exception of $\mathrm{LZ}\left(\mathrm{Ln}_{2} \mathrm{Zr}_{2} \mathrm{O}_{7}, \mathrm{Ln}=\mathrm{Tb} \sim \mathrm{Lu}\right)$ which adopts the defect fluorite structure [15]. The transition temperature depends on the radius of $\mathrm{Ln}$ ions ( $\mathrm{La}$, no transition; $\mathrm{Nd}, 2300^{\circ} \mathrm{C}, \mathrm{Sm} 2000{ }^{\circ} \mathrm{C}$, and $\left.\mathrm{Gd} 1530^{\circ} \mathrm{C}\right)$ [20].

X-ray diffraction is widely used to identify the crystal structures. Fig. 1 shows the X-ray diffraction patterns of several $\mathrm{Ln}_{2} \mathrm{Zr}_{2} \mathrm{O}_{7}$ materials at room temperature [18]. Two peaks, (331) and (511), shown in the LZ pattern originate from pyrochlore structure, and are also observed in $\mathrm{Nd}_{2} \mathrm{Zr}_{2} \mathrm{O}_{7}, \mathrm{Sm}_{2} \mathrm{Zr}_{2} \mathrm{O}_{7}$, and $\mathrm{Gd}_{2} \mathrm{Zr}_{2} \mathrm{O}_{7}$ patterns. Other peaks are commonly observed for the pyrochlore and defect fluorite structures [18]. 


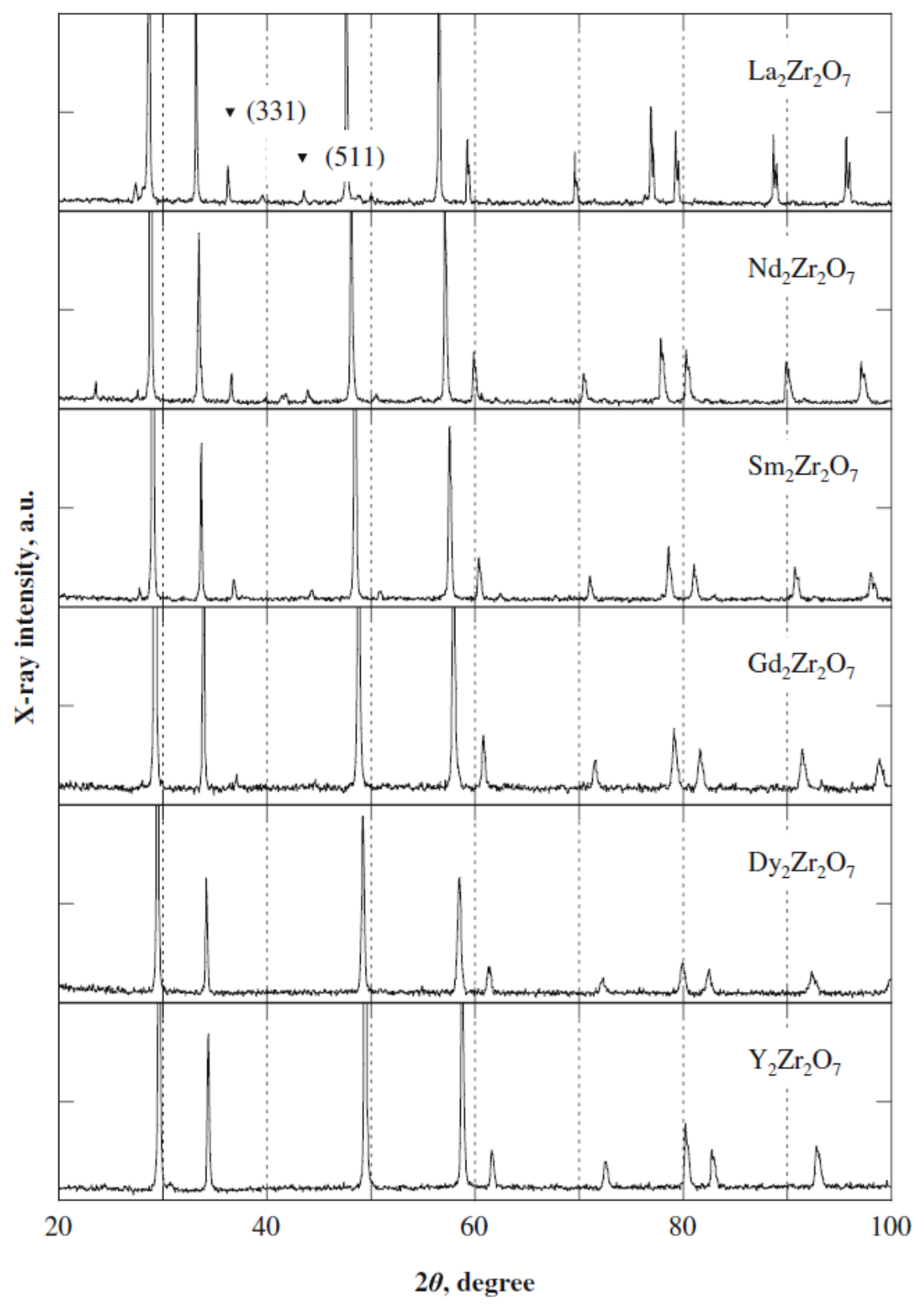

Fig. 1: X-ray diffraction patterns of $\mathrm{Ln}_{2} \mathrm{Zr}_{2} \mathrm{O}_{7}$ [18].

$\mathrm{Ln}_{2} \mathrm{Zr}_{2} \mathrm{O}_{7}$ pyrochlore crystal is a cubic structure in space group $F d \overline{3} m$ (origin choice 2) with four crystallographically independent atom sites (rear earth ion Ln, in $16 \mathrm{~d}$ at $\left(\frac{1}{2}, \frac{1}{2}, \frac{1}{2}\right)$, $\mathrm{Zr}$ in $16 \mathrm{c}$ at $(0,0,0), \mathrm{O} 1$ in $48 \mathrm{f}$ at $\left(\mathrm{x}, \frac{1}{8}, \frac{1}{8}\right)$ and $\mathrm{O} 2$ in $8 \mathrm{~b}$ at $\left(\frac{3}{8}, \frac{3}{8}, \frac{3}{8}\right)$. The structure type can be considered as an ordered defect fluorite structure with the trivalent rare earth $\mathrm{Ln}^{3+}$ and quadrivalent $\mathrm{Zr}^{4+}$ cations forming an ordered, ccp eutectic cation array. Oxygen ions are 
located at $\frac{7}{8}$ of the tetrahedral interstices: $\mathrm{O} 1$ in an off-center position within the $\mathrm{Ln}_{2} \mathrm{Zr}_{2}$ tetrahedral, $\mathrm{O} 2$ in the $\mathrm{Zr}$ tetrahedral [21]. The $\mathrm{x}$ values of $\mathrm{O} 1$ can be varied from 0.3125 to 0.375. The $\mathrm{x}$ values 0.3125 and 0.375 correspond to the regular octahedral oxygen environment around the $\mathrm{Zr}^{4+}$ ion and regular cubic oxygen environment around $\mathrm{Ln}^{3+}$ respectively. Tabira et al. determined the $\mathrm{x}$ value of $\mathrm{La}_{2} \mathrm{Zr}_{2} \mathrm{O}_{7}$ using systematic row wideangle convergent beam electron diffraction (CBED) techniques [21]. The results showed that the $\mathrm{x}$ value varied systematically with the rare earth ion radius, the larger radius corresponding to the larger $\mathrm{x}$ value. The experimental result of $\mathrm{x}$ value in $\mathrm{LZ}$ is 0.333 , according to Tabira's work [21].

The lattice parameter of a conventional cubic LZ cell can be calculated using XRD results based on Bragg's Law. Shimamura et al. reported that the lattice parameters of $\mathrm{Ln}_{2} \mathrm{Zr}_{2} \mathrm{O}_{7}$ pyrochlores increased with the ionic radius of Ln, as shown in Fig. 2 [18]. The lattice parameter of LZ is $10.8 \AA$ in Shimamura's experiments and $10.802 \AA$ in Tabira's work [21].

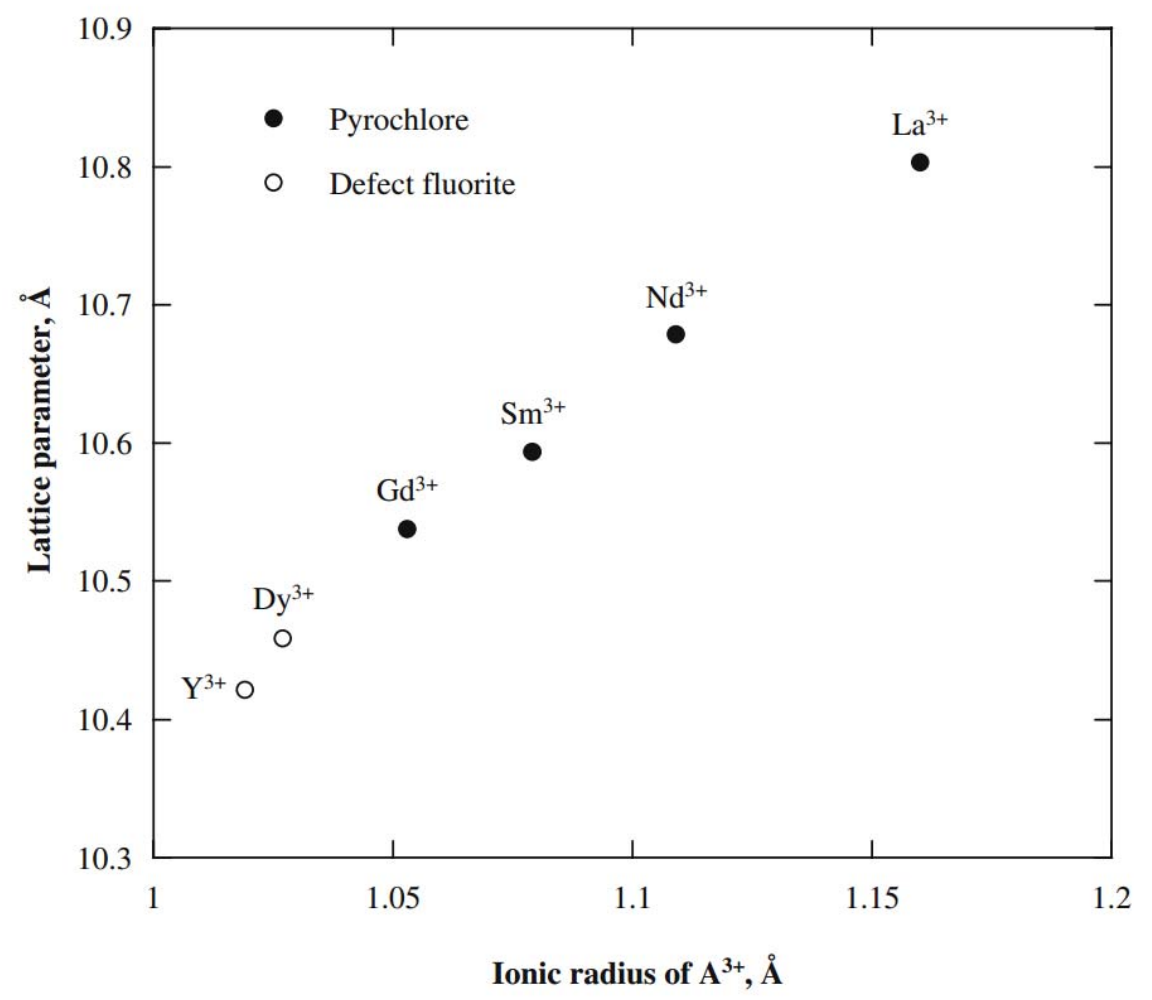

Fig. 2: Lattice parameters of $\mathrm{Ln}_{2} \mathrm{Zr}_{2} \mathrm{O}_{7}$ as a function of ionic radius. Solid and open symbols stand for pyrochlore and defect fluorite structures, respectively [18]. 


\subsection{Phase stability}

As discussed from the XRD pattern in Fig. 1, LZ has a cubic phase at room temperature. As shown in the $\mathrm{ZrO}_{2}-\mathrm{La}_{2} \mathrm{O}_{3}$ phase diagram of Fig. 3, $\mathrm{LZ}$ has no phase transformation from room temperature to its melting point [22-24]. When the molar ratio of $\mathrm{ZrO}_{2}$ and $\mathrm{La}_{2} \mathrm{O}_{3}$ becomes $2: 1$, which corresponds to $33.3 \% \mathrm{La}_{2} \mathrm{O}_{3}$, only a single $\mathrm{LZ}$ cubic phase is available from room temperature to its melting point.

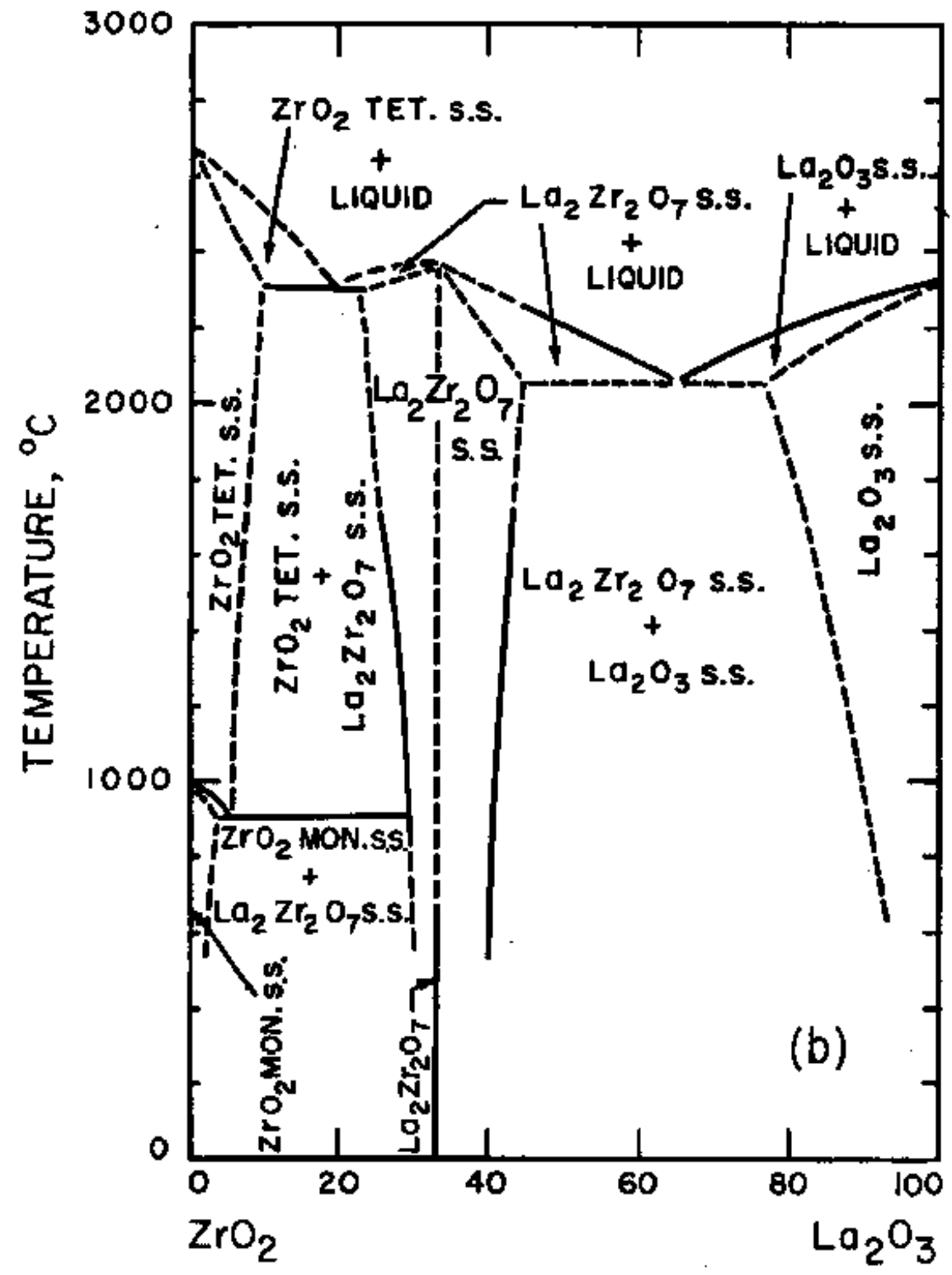

Fig. 3: Phase diagram of $\mathrm{ZrO}_{2}$ and $\mathrm{La}_{2} \mathrm{O}_{3}$ (in mole \%) [22-24]. 
In addition, in situ phase stability of LZ from room temperature to $1673 \mathrm{~K}\left(1400{ }^{\circ} \mathrm{C}\right)$ has been studied using synchrotron X-ray diffraction (XRD) at Argonne National Laboratory, as shown in Fig. 4 [25-27]. The results showed that LZ has no phase transformation in the temperature range of $303-1673 \mathrm{~K}\left(30-1400{ }^{\circ} \mathrm{C}\right)[25]$.

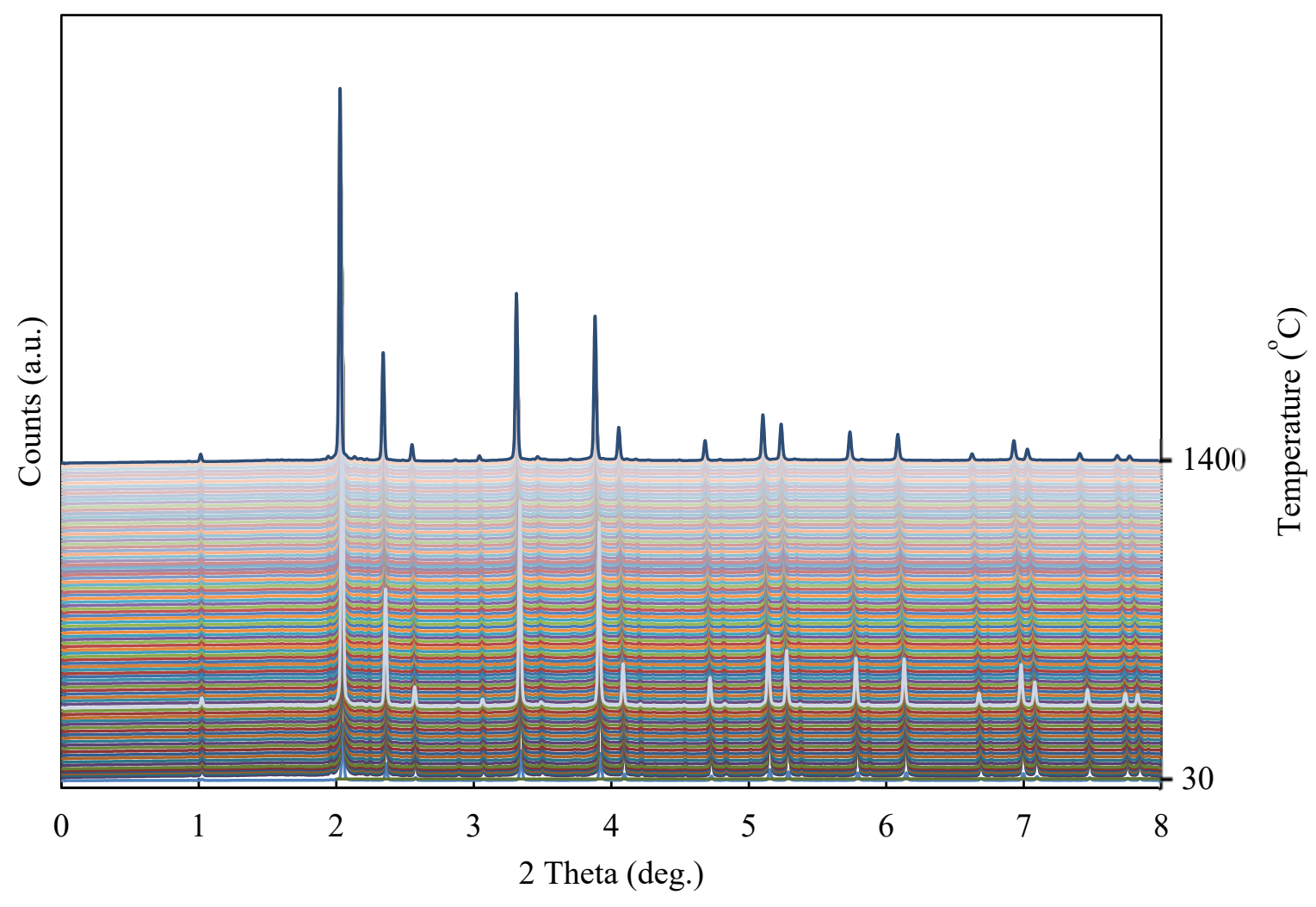

Fig. 4: in situ high energy XRD spectrum of LZ in the temperature range of $30-1400{ }^{\circ} \mathrm{C}$.

\section{Deposition techniques of lanthanum zirconate based TBCs}

\subsection{Air plasma sprayed coating}

APS is the most widely used thermal spray technique for LZ deposition. During APS process, feedstock powders are carried by noble gasses, such as Ar, to the APS torch. The thermal plasma is generated using electric arcs. Natural air is used as the source of the plasma gas for the LZ thermal spray. The essential APS parameters include current, carrier air flow rate, primary air flow rate, spray distance, powder feed rate, and substrate tangential speed [28]. 
As shown in Fig. 5, APS sprayed LZ coating has many pores and cracks, which is well known as the "splat" grains [28]. The thermal conductivity of the APS deposited coating is lower than the one from EB-PVD process, due to its "splat" grain morphology. The porosity of the LZ coating can be easily controlled by changing the spray parameters, which results in changing the thermal conductivity and the mechanical properties.

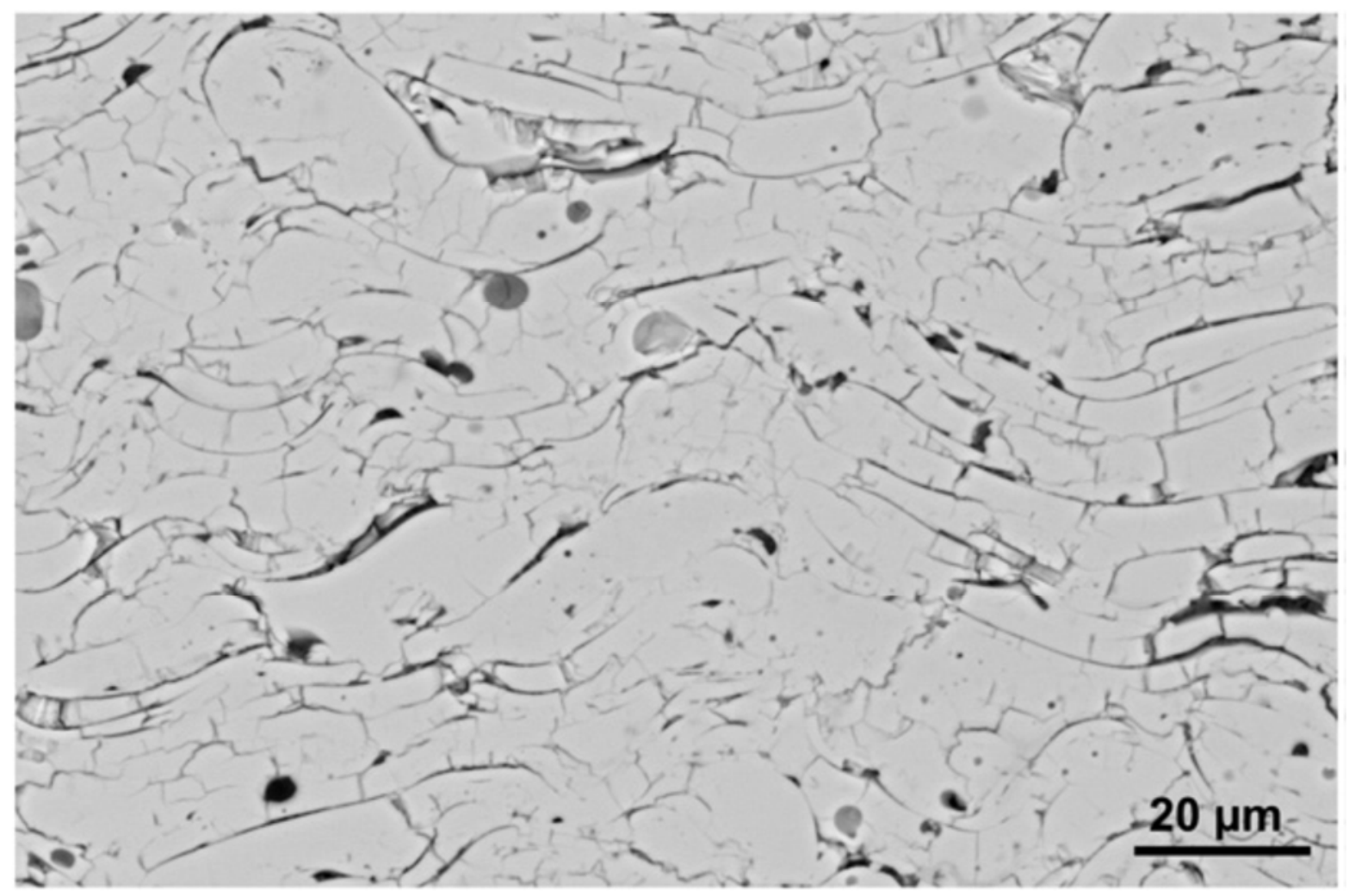

Fig. 5: Cross-sectional view of the microstructure of APS'd LZ TBC [28].

\subsection{EB-PVD deposited coating}

Another commonly used deposition technology is EB-PVD. The main EB-PVD deposition parameters include vacuum pressure, substrate distance, power supply, average substrate temperature $\left(1223 \pm 25 \mathrm{~K}, 950 \pm 25{ }^{\circ} \mathrm{C}\right)$ and substrate rotation speed [29, 30]. The overall porosity of those coatings is similar to APS coatings. The main difference is the arrangement of the pores, gaps and cracks which creates the differences in thermal conductivity. As shown in Fig. 6, the EB-PVD deposited LZ coating microstructure has a fine columnar 
microstructure that results in a higher strain tolerance [31]. Typically, EB-PVD deposited coating has a higher thermal conductivity than APS sprayed coatings at the same porosity level. The splat boundaries of APS deposited coatings act as scattering centers, and are perpendicular to the direction of heat flux. In contrast, the columnar grain boundaries in the EB-PVD deposited coatings are parallel to the direction of heat flux. As a result of higher strain tolerance, the EB-PVD deposited coatings have a good performance and considerably longer operating lifetime [7]. The main disadvantages of the EB-PVD technique are its low deposition rate, high investment costs, higher thermal conductivity, and vapor pressure requirements.

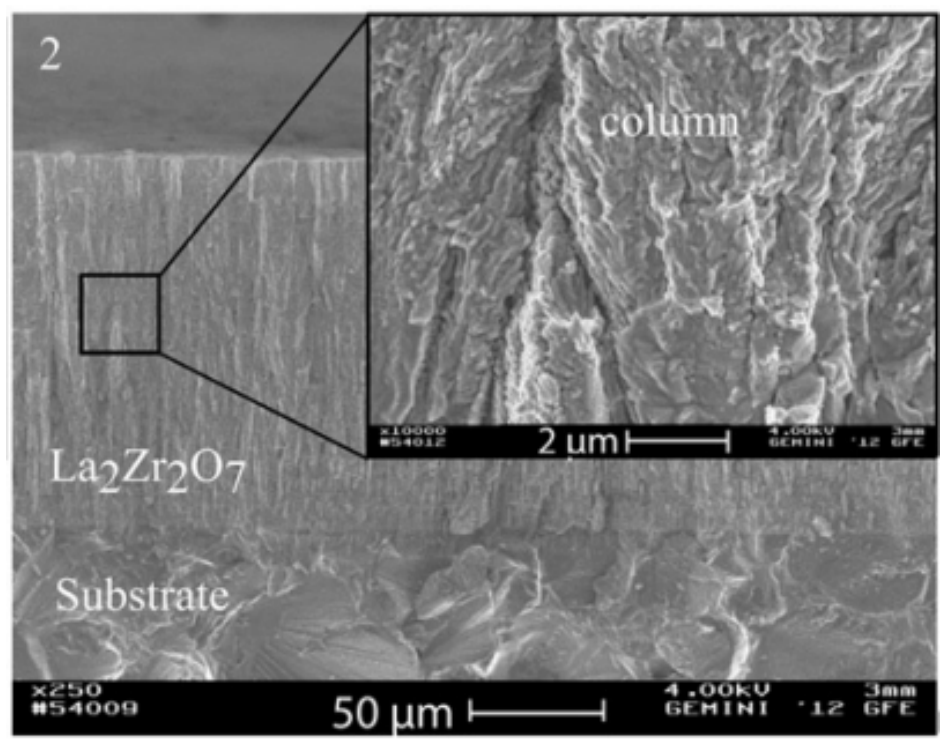

Fig. 6: Cross-sectional view of the microstructure of EB-PVD deposited LZ coating [31].

\subsection{Other deposition techniques}

In addition to the two methods mentioned above, there are other techniques to deposit LZ coatings, such as suspension plasma spray (SPS) and spray pyrolysis [7, 32, 33].

Wang et al. deposited a LZ coating using the SPS method [32]. A suspension of $30 \mathrm{wt} . \%$ nano-LZ particles in (99.5\%) ethanol was produced. Meanwhile, an electrostatic dispersant of 1 wt.\% polyethylene glycol (PEG1000) was added to the suspension. The suspension was injected into the plasma spray jet and the LZ coating was deposited. The main deposition 
parameters were standoff distance of the substrate and the concentration of the suspension feedstock. A liquid solution was used as a feedstock material instead of powder, which provided the possibility of tailoring the coating composition and the deposition of the doped multilayered coatings [33]. As shown in Fig. 7a and Fig. 7b, many pores and cracks were spotted in the microstructure of the SPS deposited coatings [32]. Weber et al. fabricated the LZ coating using the spray pyrolysis method [33]. Zirconyl oxynitrate hydrate $\left(\mathrm{ZrO}\left(\mathrm{NO}_{3}\right)_{2} \cdot x \mathrm{H}_{2} \mathrm{O}\right)$ and lanthanum nitrate hexahydrate $\left(\mathrm{La}\left(\mathrm{NO}_{3}\right)_{3} \cdot 6 \mathrm{H}_{2} \mathrm{O}\right)$ were dissolved in deionized water and further mixed in a molar ratio of 1:1 of La and Zr. The precursor solution was sprayed at the flow rate of $1 \mathrm{ml} / \mathrm{min}$ at $240{ }^{\circ} \mathrm{C}$. The deposited coatings were dried at $500 \sim 600{ }^{\circ} \mathrm{C}$ after the deposition process. As shown in Fig. 7c and Fig. 7d, many cracks were observed in the coating layer [33].
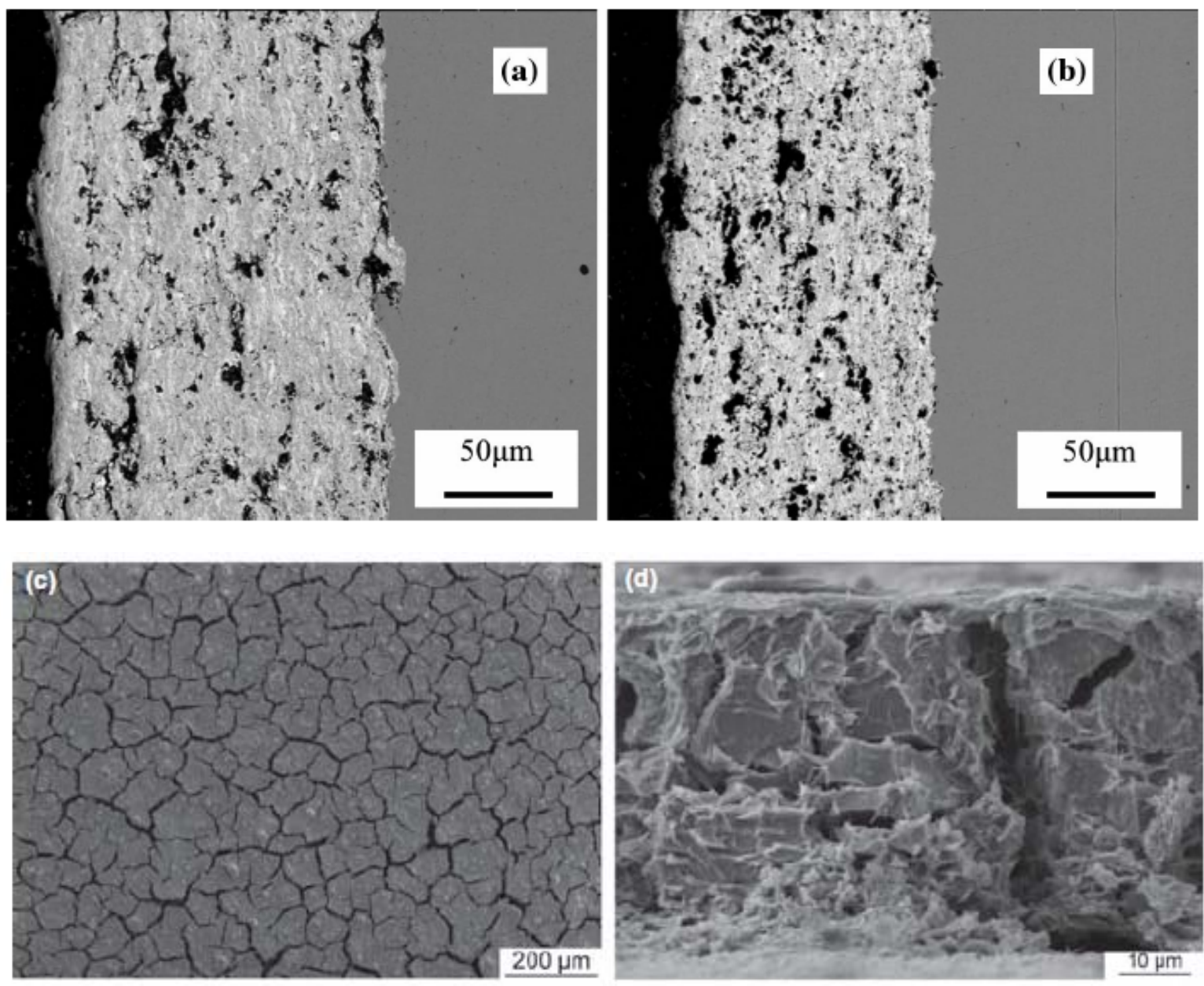
Fig. 7: Cross-sectional views of the microstructure of LZ coatings (a) SPS deposited with standoff 40mm, (b) SPS deposited with a standoff $50 \mathrm{~mm}$, and (c) surface view and (d) cross sectional view of spray pyrolysis deposited LZ coatings [32, 33]

\section{Physical properties of lanthanum zirconate based coating}

\subsection{Coating density and porosity}

The theoretical density of LZ material can be calculated using the molecular weight and the number of formula units per elementary cell [34]. Lehmann et al. calculated the theoretical density of LZ material to be $6050 \mathrm{~kg} / \mathrm{m}^{3}$ [34].

For porous LZ coatings, the density can be measured following the ASTM standard B32896, which is based on the Archimedes' principle [35]. The porosity of the LZ coating varies with the deposition parameters, such as deposition power, powder feed rate and substrate standoff distance. For APS deposited coatings, a denser coating would be produced by increasing the power used in the torch, or increasing powder feed ratio, or reducing standoff distance. Commercial APS deposited coating shows an average porosity of 15 25\%. However, it is important to tailor the porosity of the $\mathrm{LZ}$ coating in a range of $8 \sim 19 \%$ to acquire good thermal and mechanical properties [36].

\subsection{Sintering behavior}

Sintering of porous ceramic coating is the process in which the coating is densified by the reduction in surface energy associated with the excess surface area of the pores and cracks [2]. Sintering of the porous TBCs normally occurs at elevated temperatures. When sintering occurs, densification process inevitably increases the elastic modulus and thereby decreases the strain compliance of the coating. Meanwhile the thermal conductivity of the coating increases due to the decrease of the porosity [2].

Many experimental approaches can be used to quantify the sintering behaviors: 1) measure the dimensional change of the coating sample using a high-temperature dilatometer; 2) determine porosity distribution and its change using a mercury porosimetry; 3) measure the relative density of the coating during the sintering process based on the Archimedes' principle; 
4) derive from the measured thermal conductivity changes during long time heating periods at various temperatures $[10,37,38]$. Vassen et al. investigated the sintering behavior of APS deposited LZ coating at temperatures as high as $1650{ }^{\circ} \mathrm{C}$ using the high-temperature dilatometer and the mercury porosimetry methods $[10,37]$. Higher porosity led to higher sintering rate. The coating with a porosity of $20 \%$ densified substantially during an annealing process at $1250^{\circ} \mathrm{C}$ [37]. Vassen et al. commented that decrease in porosity might lead to a better thermomechanical behavior [10]. Zhu et al. investigated the sintering behavior by continuously monitoring the thermal conductivity evolution [38]. Zhu found that the LZ coating showed a significant thermal conductivity increase (from $0.55 \mathrm{~W} / \mathrm{m} / \mathrm{K}$ to $0.95 \mathrm{~W} / \mathrm{m} / \mathrm{K}$ in $20 \mathrm{hrs}$.) at $1575^{\circ} \mathrm{C}$, suggesting the coating was undergoing substantial sintering. Nair et al. also studied the sintering behavior of LZ coating [39]. They found that the major mechanism of the sintering process was surface diffusion, in the temperature range of $800-1100{ }^{\circ} \mathrm{C}$. Sintering above $1100{ }^{\circ} \mathrm{C}$ was mainly because of grain boundary diffusion combined with surface diffusion. The contribution from surface diffusion became negligible as the sintering temperature increased.

In general, the sintering resistance of LZ coating is higher than that of YSZ coating, and also $\mathrm{BaZrO}_{3}$ and $\mathrm{SiZrO}_{3}$ coatings $[10,37]$. The low-sintering activity of the $\mathrm{LZ}$ is beneficial for TBC applications.

\subsection{Crack and pore morphology}

The crack and pore morphology of TBCs is a crucial parameter affecting the thermal and mechanical properties of the coatings. Cracks can be categorized as horizontal, vertical, and spherical forms. Zhang et al. studied the crack morphology of the APS deposited LZ coating using a quantitative imaging analysis method [40]. It was found that the cracks were primarily horizontal in the top and middle regions of the cross section area, while vertical cracks became dominant in the bottom region. In addition, the calculated porosities showed a non-uniformity in the cross sectional area.

Weber et al. showed that vertical crack is beneficial in LZ TBC application due to enhanced thermomechanical compliance $[3,41]$. The LZ based TBCs were deposited using the spray pyrolysis method, and the vertical cracks were introduced by decomposing the metal salt and 
drying the coating layer at $575^{\circ} \mathrm{C}$, as shown in Fig. 7 d. Moreover, the multilayer coating with vertical cracks was fabricated by the successive deposition and decomposition of multiple thin layers. Heat conduction was small in this multilayer coating due to the generated cracks, and the thermal durability can be increased due to the increased thermo-mechanical compliance [41].

\section{Thermal properties of lanthanum zirconate based coating}

\subsection{Melting point and specific heat capacity}

Melting point is an important criterion for selecting TBC materials, which is critical for the thermal stability in high-temperature operation environments. Thermal analysis is the commonly used method to detect the melting point, which is performed in sealed tungsten crucibles, and the sample temperature is monitored by a spectro-pyrometer. In addition, hightemperature X-ray diffraction experiments, e.g., in Advanced Photon Source at Argonne National Laboratory, can also be used to determine the melting temperature by monitoring the pyrochlore (111) peaks $[42,43]$. As shown in Table 1, the experimentally measured melting point of the LZ is approximately $2523-2573 \mathrm{~K}\left(2250-2300{ }^{\circ} \mathrm{C}\right)$, which is lower than that of YSZ $\left(2953 \mathrm{~K}, 2680^{\circ} \mathrm{C}\right)[10,37,42]$. Although the melting point of $\mathrm{LZ}$ is lower than that of YSZ, it is still sufficiently high for most TBC applications.

Table 1: Thermal properties of $\mathrm{La}_{2} \mathrm{Zr}_{2} \mathrm{O}_{7}$ coating vs. YSZ coating

\begin{tabular}{|c|c|c|}
\hline & $\mathrm{LZ}$ & YSZ \\
\hline Melting point & 2523-2573 K (Vassen [10, 37], Hong [42]) & $\begin{array}{c}2953 \mathrm{~K} \\
\text { (Vassen [10]) }\end{array}$ \\
\hline Specific heat capacity & $\begin{array}{c}0.48 \text { J/g/K (@1200 K, Vassen [10]) } \\
0.41 \text { J/g/K (@400 K, Bolech [16]) } \\
0.42 \text { J/g/K (@400 K, Sedmidubsky [17]) } \\
0.44 \text { J/g/K (@1200 K, Girolamo [28]) }\end{array}$ & 0.65 J/g/K (@1200 K, Khor [44]) \\
\hline Thermal conductivity & $\begin{array}{c}1.55 \text { W/m/K (dense, @1273 K, Vassen } \\
[10]) \\
2.15 \text { W/m/K (dense, @ } 1273 \text { K, Zhu [38]) }\end{array}$ & $\begin{array}{c}2.25 \text { W/m/K (dense @ } 1273 \mathrm{~K} \\
\text { Vassen [10]) }\end{array}$ \\
\hline
\end{tabular}




\begin{tabular}{|c|c|c|}
\hline & $\begin{array}{c}0.68 \mathrm{~W} / \mathrm{m} / \mathrm{K} \text { (porosity } 11.54 \%, @ 1173 \mathrm{~K}, \\
\text { Guo [45]) } \\
0.87 \mathrm{~W} / \mathrm{m} / \mathrm{K} \text { (porous, @ } 1273 \mathrm{~K}, \text { Bobzin } \\
\text { [31]) }\end{array}$ & $\begin{array}{l}0.88 \text { W/m/K (Porous, @ } 1173 \mathrm{~K} \text {, } \\
\text { Guo [45]) } \\
1.38 \text { W/m/K (porous, @ } 1273 \mathrm{~K}, \\
\text { Bobzin [31]) }\end{array}$ \\
\hline $\begin{array}{c}\text { Coefficient of } \\
\text { thermal expansion }\end{array}$ & $\begin{array}{c}9.45 \times 10^{-6} / \mathrm{K}(273-1473 \mathrm{~K}, \text { Chen [46]) } \\
9-10 \times 10^{-6} / \mathrm{K}(400-1600 \mathrm{~K}, \text { Guo [45] }) \\
9.0-9.7 \times 10^{-6} / \mathrm{K}(400-1600 \mathrm{~K}, \text { Zhang [47]) } \\
7.6-9.1 \times 10^{-6} / \mathrm{K}(400-1400 \mathrm{~K}, \text { Lehmann } \\
[34])\end{array}$ & $\begin{array}{c}11 \times 10^{-6} / \mathrm{K} \text { (dense } @ 1273 \mathrm{~K}, \\
\text { Vassen }[10]\end{array}$ \\
\hline
\end{tabular}

Differential scanning calorimetry (DSC) is the most widely used technique to precisely measure the specific heat capacity $\left(C_{p}\right)$. Several researchers investigated the specific heat capacity of LZ in different conditions, as shown in Fig. 8 [10, 16, 17, 28, 48, 49]. In Vassen 's work, the LZ samples were densified by hot pressing at $1350 \sim 1400{ }^{\circ} \mathrm{C}$. LZ samples in powder form were used in Bolech and Sedmidubsky's work. In Girolamo's work, the specific heat of the LZ coating with a porosity of $11 \%$ was measured. The specific heat of $8 Y S Z$ is $\sim 0.55-$ $0.65 \mathrm{~J} / \mathrm{g} / \mathrm{K}$ in the temperature range of $300-1200{ }^{\circ} \mathrm{C}$, which is larger than that of the $\mathrm{LZ}$ [44]. For the TBC materials, small $\mathrm{Cp}$ values are preferred to reduce thermal diffusivity.

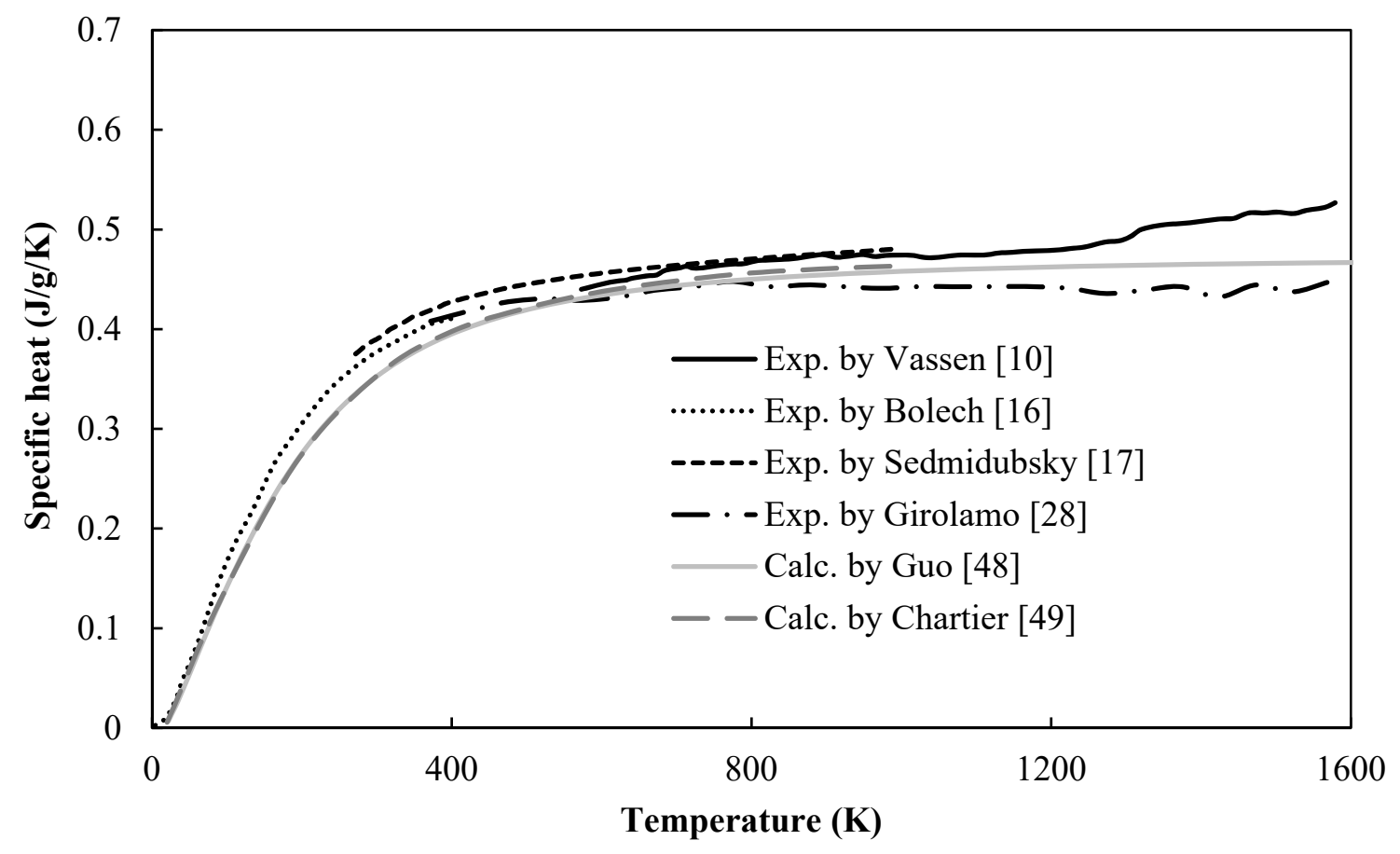


Fig. 8: Specific heat capacity $\left(\mathrm{C}_{\mathrm{p}}\right)$ of $\mathrm{LZ}$ in the temperature range from $0 \sim 1600 \mathrm{~K} .[10,16,17,28,48,49]$. Notice that Guo and Chartier's $\mathrm{C}_{\mathrm{p}}$ curves are overlapped below $1000 \mathrm{~K}$.

\subsection{Thermal conductivity}

For TBC materials, thermal conductivity is the most important material property. Thermal conductivity can be determined using thermal diffusivity, specific heat capacity and density, which can be independently measured experimentally. The most widely used experimental method to measure the thermal diffusivity is the laser-flash method. Vassen et al. measured the thermal conductivity of LZ samples using the laser-flash method, in which samples were prepared by hot pressing in the temperature range of $1350-1400^{\circ} \mathrm{C}[10,34]$. The density of the hot pressed sample was greater than $95 \%$. The thermal conductivity that Vessen measured was $\sim 1.5-2.0 \mathrm{~W} / \mathrm{m} / \mathrm{K}$ in the temperature range of $200-1400{ }^{\circ} \mathrm{C}$. Zhu et al. did similar studies for the hot pressed disk-shape samples using the spray-dried LZ powders [38, 50]. The measured thermal conductivities of the densified LZ were 2.0-4.0 W/m/K, which were larger than Vessen's results, in the temperature range of $200-1400{ }^{\circ} \mathrm{C}$. The thermal conductivity is very sensitive to porosity level. A low porosity leads to a high thermal conductivity. The high thermal conductivity in Zhu's work may be due to the coating's lower porosity than that in Vassen's work. Guo et al. measured the thermal conductivities of APS deposited LZ coating with a porosity of $11.54 \%$ using the laser-flash method [45]. The measured average thermal conductivity of the porous $\mathrm{LZ}$ was $\sim 0.59-0.68 \mathrm{~W} / \mathrm{m} / \mathrm{K}$ in the temperature range of $297-1172$ $\mathrm{K}\left(24-899^{\circ} \mathrm{C}\right)$. Chen et al. also measured the thermal conductivity of APS deposited LZ coating with a lower porosity [46]. Bobzin et al. investigated the thermal conductivity of mixed 7 wt.\% YSZ and $\mathrm{La}_{2} \mathrm{Zr}_{2} \mathrm{O}_{7}$ layers deposited by the EB-PVD method [31]. All of the experimental data and a modeling result [51] (see section 8.1 for thermal conductivity modeling details) are compiled in Fig. 9.

As shown in Fig. 9, the thermal conductivities of the LZ coating decrease with the increase of temperature till $1200 \mathrm{~K}$ due to lattice scattering, and the conductivities increase again above $1200 \mathrm{~K}$ due to radiation contribution. The conductivities also depend on coating porosity [10, $31,38,45,46,51]$. In Vassen and Zhu's works, the porosities of the LZ samples were very low so the thermal conductivities were much larger than those of the porous coatings in Guo, Bobzin and Chen's research. 


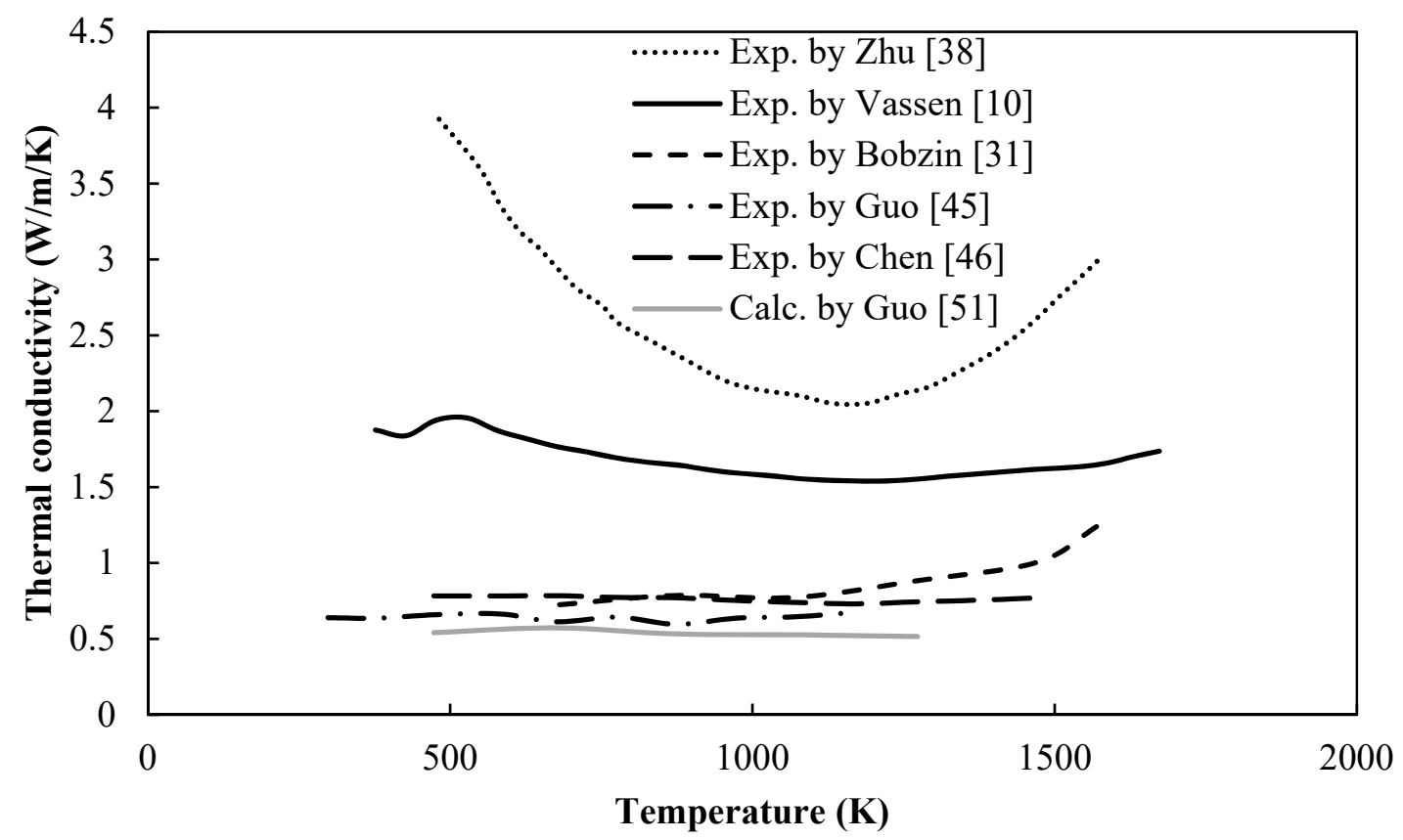

Fig. 9: Thermal conducitivity of $\mathrm{LZ}$ in the temperature range of $273-1700 \mathrm{~K}[10,31,38,45,46,51]$.

In addition to porosity, doped LZ materials were developed to further reduce the thermal conductivity and improve thermal cycling and mechanical properties. Lanthanide elements are possible dopants because they form a similar pyrochlore structure with $\mathrm{ZrO}_{2}$. Lehmann et al. showed that the thermal conductivities of the $\mathrm{Nd}, \mathrm{Eu}, \mathrm{Gd}$ and Dy doped $\mathrm{LZ}\left(30 \%\right.$ of $\mathrm{La}^{3+}$ was substituted) were lower than that of pure LZ below $1000^{\circ} \mathrm{C}$ [34]. Lehmann noted that the thermal conductivity was affected by the atomic mass and radius of the substituted and substituting atoms. Bansal et al. suggested that $\mathrm{Gd}$ and $\mathrm{Yb}$ can replace the $\mathrm{La}^{3+}$ cation to form new pyrochlore structured materials such as $\mathrm{La}_{1.7} \mathrm{Yb}_{0.3} \mathrm{Zr}_{2} \mathrm{O}_{7}$, $\mathrm{La}_{1.7} \mathrm{Gd}_{0.3} \mathrm{Zr}_{2} \mathrm{O}_{7}$ and $\mathrm{La}_{1.7} \mathrm{Gd}_{0.15} \mathrm{Yb}_{0.15} \mathrm{Zr}_{2} \mathrm{O}_{7}$ [50]. The $\mathrm{Gd}$ and $\mathrm{Yb}$ doped $\mathrm{LZ}$ showed a lower thermal conductivity, a better high-temperature stability up to $1650{ }^{\circ} \mathrm{C}$ and a better sintering resistance than LZ. In addition, $\mathrm{Yb}, \mathrm{Ce}, \mathrm{Y}$, In and Sc were reported as dopants for both $\mathrm{La}^{3+}$ and $\mathrm{Zr}^{4+}$ site [52, 53]. Xiang et al. showed that $\left(\mathrm{La}_{0.7} \mathrm{Yb}_{0.3}\right)_{2}\left(\mathrm{Zr}_{0.7} \mathrm{Ce}_{0.3}\right)_{2} \mathrm{O}_{7}$ and $\left(\mathrm{La}_{0.2} \mathrm{Yb}_{0.8}\right)_{2}\left(\mathrm{Zr}_{0.7} \mathrm{Ce}_{0.3}\right)_{2} \mathrm{O}_{7}$ had lower thermal conductivities than LZ [53]. Wang found that $\left(\mathrm{La}_{1-\mathrm{x} 1} \mathrm{Y}_{\mathrm{x} 1}\right)_{2}\left(\mathrm{Zr}_{1-\mathrm{x} 2} \mathrm{Y}_{\mathrm{x} 2}\right)_{2} \mathrm{O}_{7},\left(\mathrm{La}_{1-}\right.$ $\left.{ }_{x 1} \operatorname{In} 1_{x 2}\right)_{2}\left(\mathrm{Zr}_{1-\mathrm{x} 2} \mathrm{In}_{\mathrm{x} 2}\right)_{2} \mathrm{O}_{7}$ and $\left(\mathrm{La}_{1-\mathrm{x} 1} \mathrm{Sc}_{\mathrm{x} 1}\right)_{2}\left(\mathrm{Zr}_{1-\mathrm{x} 2} \mathrm{Sc}_{\mathrm{x} 2}\right)_{2} \mathrm{O}_{7}$ had the potential to achieve lower thermal conductivity than LZ [52]. 
Low thermal conductivity is the primary advantage of LZ coatings over the YSZ coatings. Vassen et al. compared the thermal conductivity of hot pressed YSZ and LZ samples [10]. Vassen noted that high dense LZ samples' thermal conductivities were 30-35\% lower than YSZ at $800-1000{ }^{\circ} \mathrm{C}$, in the similar porosity level. Bobzin et al. showed that the thermal conductivity of EB-PVD deposited 7YSZ was about 25-40\% higher than the EB-PVD deposited LZ coating [31]. Guo et al. showed that the thermal conductivity of APS deposited porous LZ coating was $\sim 25 \%$ lower than that of APS deposited porous $8 \mathrm{YSZ}$ coating [45].

\subsection{Coefficient of thermal expansion}

TBC is a multi-layer material system including alloy, intermetallic bond coat, TGO layer and ceramic top coat, therefore the volume change in the thermal cycling process is different due to the different CTEs in each layer. Thermally induced residual stress generated among TBC layers due to CTE mismatch becomes a primary cause of failure [9]. Since the CTE values of superalloy substrate and bond coat are usually about $15 \times 10^{-6}$ and $14 \times 10^{-6} / \mathrm{K}$, respectively, at $1000{ }^{\circ} \mathrm{C}[4,9]$, which are much larger than the typical ceramic top coat. As a result, large CTEs are preferred for the ceramic top coat to reduce CTE mismatch. Additionally, due to large thickness of substrate, its CTE influence may be more important than bond coat.

The most widely used approach to measure CTEs is the dilatometry method. The linear CTE value can be obtained from the measurement of the temperature-dependent sample length change using a high-temperature dilatometer. Many researchers measured the CTEs of LZ using a dilatometer, as summarized in Fig. 10 and Table 1 [34, 45-47, 54]. Chen et al. investigated the CTEs of both bulk LZ material and APS deposited LZ coating, and the results showed a similar trend [46]. The apparent CTE value of the LZ coating was about $9.45 \times 10^{-6}$ $/ \mathrm{K}$ in the temperature range of $0 \sim 1200{ }^{\circ} \mathrm{C}$. Guo et al. also measured the CTE of LZ coating. The average porosity of the APS deposited LZ coating in Guo's measurement was $11.54 \%$ [45]. Zhang et al. determined the CTE value of LZ powders by measuring variation of lattice parameters during heating process [47]. The lattice parameters came from the XRD analysis at different temperatures. Lehmann, using a dilatometer, investigated the CTE of hot pressed LZ samples with a relative density between $69 \%$ and $93 \%$ [34]. 


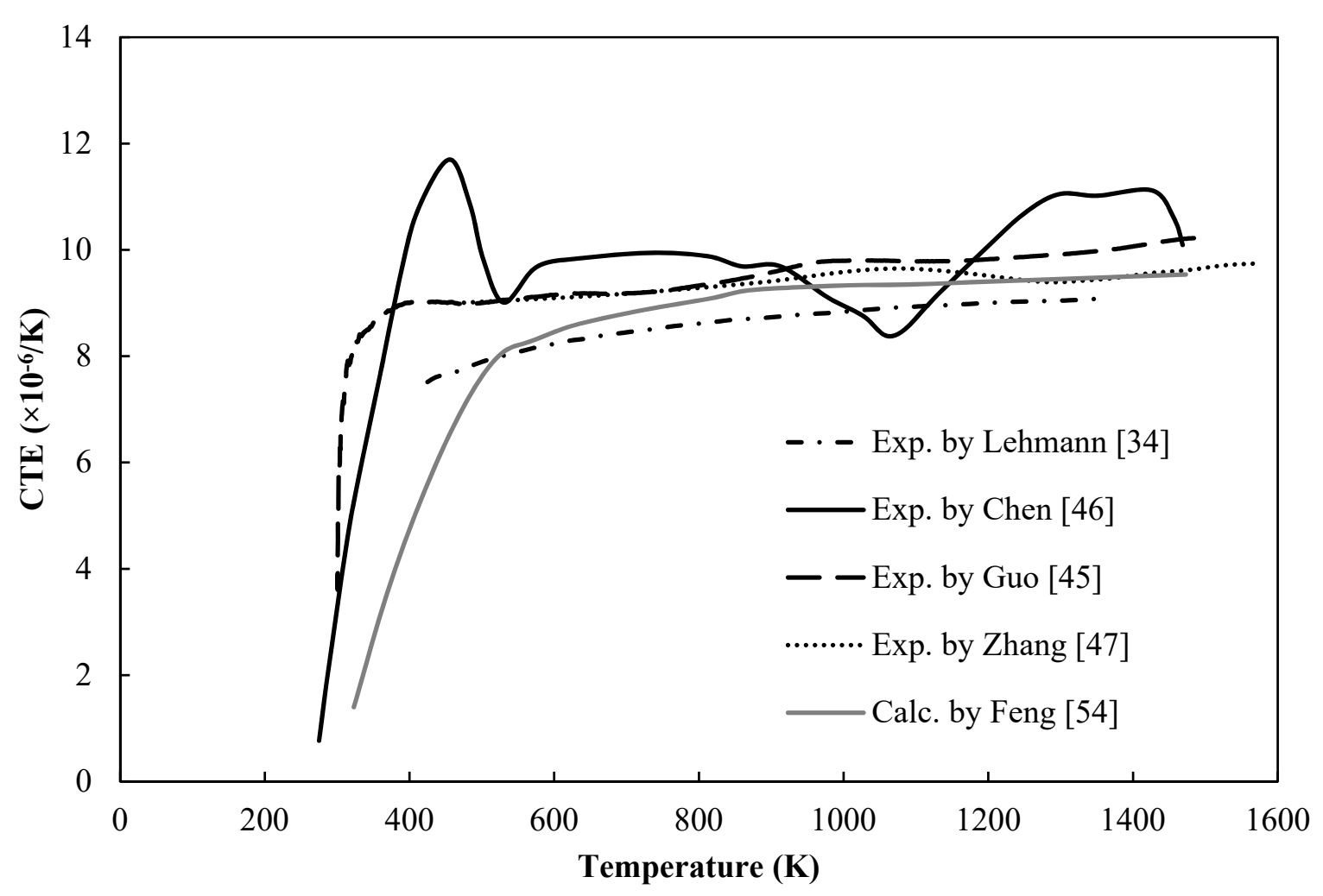

Fig. 10: CTEs of LZ in the temperature range of $273-1600 \mathrm{~K}$. [34, 45-47, 54].

The CTEs of pure LZ are lower than that of YSZ $\left(11 \times 10^{-6} / \mathrm{K}\right.$ at $\left.1000^{\circ} \mathrm{C}\right)[10]$. As a result, the CTE difference between the LZ top coat and bond coat in LZ based TBC system is larger than that between the YSZ top coat and the bond coat in YSZ TBCs. This is a disadvantage for $\mathrm{LZ}$ in TBC applications because this may lead to a large volume change during thermal cycling process. However, CTE values of the LZ based coating can be increased by doping with selected rare earth element dopants. For example, Xiang et al. showed that the CTEs of $\left(\mathrm{La}_{0.7} \mathrm{Yb}_{0.3}\right)_{2}\left(\mathrm{Zr}_{0.7} \mathrm{Ce}_{0.3}\right)_{2} \mathrm{O}_{7}$ and $\left(\mathrm{La}_{0.2} \mathrm{Yb}_{0.8}\right)_{2}\left(\mathrm{Zr}_{0.7} \mathrm{Ce}_{0.3}\right)_{2} \mathrm{O}_{7}$ were higher in the hightemperature range (above $400{ }^{\circ} \mathrm{C}$ ) than that of pure LZ [53]. Meanwhile, Cao and Zhang suggested that using $\mathrm{Ce}(5 \sim 20 \%)$ to dope into LZ to increase the CTE value $[47,55]$. 


\section{Mechanical properties of lanthanum zirconate based coating}

\subsection{Elastic properties}

Elastic properties include Young's modulus $(E)$, bulk modulus $(K)$, and shear modulus $(G)$. These elastic properties can be measured by using the depth-sensing micro- and nanoindentation technique or the ultrasound pulse-echo method $[10,18]$. In the micro-indentation technique, $E$ can be obtained from the slope of unloading stress-strain curve by adopting Sneddon's flat-ended cylindrical punch model [10]. Shimamura et al. studied the moduli of a series of $\mathrm{Ln}_{2} \mathrm{Zr}_{2} \mathrm{O}_{7}$ materials using the ultrasound pulse-echo measurement [18]. Shimamura found that the elastic moduli (except for the Poisson's ratio) strongly depend on the atomic radius of rare earth elements in the lanthanide zirconate pyrochlore $\mathrm{Ln}_{2} \mathrm{Zr}_{2} \mathrm{O}_{7}$. A larger atomic radius corresponds to higher $E, K$, and $G$ values. La has a larger atomic radius than $\mathrm{Nd}, \mathrm{Sm}$ and $\mathrm{Gd}$, so $\mathrm{LZ}$ has larger elastic modulus than $\mathrm{Nd}_{2} \mathrm{Zr}_{2} \mathrm{O}_{7}, \mathrm{Sm}_{2} \mathrm{Zr}_{2} \mathrm{O}_{7}$ and $\mathrm{Gd}_{2} \mathrm{Zr}_{2} \mathrm{O}_{7}$ [18].

Many researchers measured the elastic moduli of the LZ powder and coating, as summarized in Table 2. The sample used in Vassen's work was prepared by pressing $\mathrm{La}_{2} \mathrm{Zr}_{2} \mathrm{O}_{7}$ powders in the temperature range of $1350 \sim 1400{ }^{\circ} \mathrm{C}$. Zhang et al. measured APS deposited LZ coating with a porosity of $7.53 \%$ [26]. Xu et al. investigated $E$ values of EB-PVD deposited LZ coating [56]. Shimamura et al. used LZ powder samples and measured using the ultrasound pulse-echo method [18]. Girolamo et al. tested APS deposited LZ coating, which was exposed at $1350{ }^{\circ} \mathrm{C}$ for $50 \mathrm{~h} \mathrm{[28]}$.

The Young's moduli of hot pressed LZ sample are about $15 \%$ lower than that of the hot pressed $8 \mathrm{YSZ}$, which is $\sim 210 \pm 10 \mathrm{GPa}$. The low Young's moduli of LZ are advantageous for reducing thermal stresses, which might compensate CTE mismatch in coatings [10].

\subsection{Hardness and fracture toughness}

Hardness test can be classified into three categories according to the length scale applied in the measurement: macroindentation hardness, microindentation hardness, and nanoindentation hardness. The measured hardness data of LZ coatings are listed in Table 2. The samples used in each researcher's work are the same as aforementioned in section 6.1. 
The hardness of LZ varies significantly due to the sample density change. The hardness increases with increasing coating density.

Fracture toughness $\left(K_{I C}\right)$ is a material property which describes the ability of fracture resistance to maintain cracks in the material without crack propagation. The standard measurement method of $K_{I C}$ is the four-point bending test of bulk samples. Another alternative technique is the indentation method, which is widely used to evaluate the $K_{I C}$ values of ceramic and coating systems [52]. The $K_{I C}$ values of LZ powders and coatings are summarized in Table 2.

Hot pressed 8YSZ has higher hardness and $K_{I C}$ than LZ (microindentation hardness of densified $8 \mathrm{YSZ}$ is $13 \pm 1 \mathrm{GPa}, K_{I C}$ of densified $8 \mathrm{YSZ}$ is $\left.2.0-3.3 \mathrm{MPa} \cdot \mathrm{m}^{1 / 2}\right)[10,57]$. The low $K_{I C}$ is the major disadvantage of $\mathrm{LZ}$, which leads to a severe limit on its application as a TBC material.

To improve the $K_{I C}$ of $\mathrm{LZ}$ material, a composite or multilayer LZ coating can be used. Jiang et al. studied the microstructure and mechanical properties of $\mathrm{LZ}-\mathrm{Zr}_{0.92} \mathrm{Y}_{0.08} \mathrm{O}_{1.96}$ composite ceramics, which were prepared by spark plasma sintering at $1450{ }^{\circ} \mathrm{C}$. The results revealed that the composite ceramics had a higher $K_{I C}$ than single phase LZ [58]. Jiang et al. also showed that the KIC of composite LZ and 4YSZ coatings increased with increasing the content of $4 \mathrm{YSZ}$. The $\mathrm{K}_{\mathrm{IC}}$ reached to a value of $1.8 \pm 0.1 \mathrm{MPa} \mathrm{m}^{1 / 2}$ for $50 \% 4 \mathrm{YSZ}$ plus $50 \%$ $\mathrm{LZ}$ composite coating, which is about two times of that of single phase $\mathrm{La}_{2} \mathrm{Zr}_{2} \mathrm{O}_{7}$ coating.

Guo et al. compared single LZ and double-layer LZ-8YSZ coatings [45]. The results showed that the double-layer coating composed of LZ plus porous 8YSZ substantially improved the durability in thermal cycling tests, suggesting the bi-layer design is a feasible solution to improve the fracture toughness in LZ based coatings.

Table 2: Mechanical properties of LZ coating vs. YSZ coating

\begin{tabular}{|c|c|c|}
\hline & LZ & YSZ \\
\hline \multirow{3}{*}{ Young's modulus } & $175 \pm 11 \mathrm{GPa}$ (densified powder, Vassen [10]) & $210 \pm 10 \mathrm{GPa}$ \\
& $156 \pm 10 \mathrm{GPa}$ (coating, Zhang [26]) & (densified powder, \\
& $153 \mathrm{GPa}$ (coating, Xu [56]) & Vassen [10]) \\
\hline
\end{tabular}




\begin{tabular}{|c|c|c|}
\hline & $\begin{array}{c}280 \mathrm{GPa} \text { (powder, Shimamura [18]) } \\
141 \mathrm{GPa} \text { (porous coating, Girolamo [28]) }\end{array}$ & \\
\hline Bulk modulus & $216 \mathrm{GPa}$ (Shimamura [18]) & - \\
\hline Shear modulus & 109 GPa (Shimamura [18]) & - \\
\hline Poisson's ratio & 0.28 (Shimamura [18]) & - \\
\hline Vicker's hardness & $\begin{array}{c}5.51 \pm 0.25 \mathrm{GPa} \text { (coating, Zhang [26]) } \\
8.83 \mathrm{GPa} \text { (coating, } \mathrm{Xu}[56])\end{array}$ & - \\
\hline $\begin{array}{l}\text { Microindentation } \\
\text { hardness }\end{array}$ & $9.9 \pm 0.4 \mathrm{GPa}($ densified powder, Vassen $[10])$ & $\begin{array}{c}13 \pm 1 \mathrm{GPa} \\
\text { (densified powder, } \\
\text { Vassen [10]) }\end{array}$ \\
\hline $\begin{array}{l}\text { Nanoindentation } \\
\text { hardness }\end{array}$ & $8.8 \pm 2.1 \mathrm{GPa}$ (coating, Zhang [26]) & - \\
\hline Fracture toughness & $\begin{array}{c}1.1 \pm 0.2 \mathrm{MPa} \mathrm{m}^{1 / 2} \text { (densified powder, Vassen [10]) } \\
\left.1.84 \mathrm{MPa} \mathrm{m}^{1 / 2} \text { (coating, } \mathrm{Xu}[56]\right) \\
0.9 \mathrm{MPa} \mathrm{m}{ }^{1 / 2} \text { (densified powder, Jiang [58]) }\end{array}$ & $\begin{array}{c}2.0-3.3 \mathrm{MPa} \cdot \mathrm{m}^{1 / 2} \\
(\text { Beshish [57]) }\end{array}$ \\
\hline
\end{tabular}

\section{Thermal, mechanical, chemical and durability analyses}

\subsection{Thermal cycling test}

Thermal cycling tests are applied to simulate the operation environment of TBCs in gas turbines. Thermal cycling tests can be sorted into two broad categories based on temperature gradient during thermal process [59]. (1) A constant temperature distribution in the sample without a gradient in TBC samples. When heating/cooling rates are low, such as the furnace cycling test (FCT), the sample is slowly heated in a furnace, which creates a high-temperature isothermal environment for the entire TBC system, and then it is cooled by the compressed gas or ambient air cooling out of the furnace [60]. (2) The thermal cycling tests with a temperature gradient across the sample due to fast heating/cooling, such as the jet engine thermal shock (JETS) test, laser rig and flame rig [59]. In the JETS test, a typical cycle consists of a $20 \mathrm{~s}$ heating process, a $20 \mathrm{~s}$ forced nitrogen gas cooling and a $40 \mathrm{~s}$ dwell cooling in ambient air environment. The front surface temperature can reach $1400{ }^{\circ} \mathrm{C}$. The failure 
criterion in the JETS tests is more than $20 \%$ spallation of the TBC sample. Since the back side of the sample is not heated, a thermal gradient is generated in the TBC samples during the JETS test. The temperature gradient in the JETS over the whole sample depends on the thickness of the coating system, coating composition, porosity, and microstructure of the coating [60].

Although the maximum temperature and the heating and cooling duration time vary in different thermal cycling tests, large thermal stress and strain mismatch generated due to the CTE mismatch between the top and bond coats are the principal reason for the failure of LZ coatings. To obtain a long thermal cycling lifetime, the LZ coating needs to accommodate the thermal strain associated with thermal cycling [2]. In addition, oxidation of bond coat and low $K_{I C}$ of $\mathrm{LZ}$ are additional factors for the spallation of the LZ coating [45, 61].

Many researchers have conducted thermal cycling tests of LZ in different testing conditions. Because the TBC is a complicated system, the thermal cycling results vary due to different cycling test parameters, coating porosities, coating microstructures, multilayer coating architectures, and coating compositions, etc. Vassen et al. conducted thermal cycling test with a large temperature gradient across the sample [10, 37, 62]. The APS deposited LZ coating with single-layer coatings and the APS double-layer coatings with YSZ plus LZ top coat were used in these tests. These TBC systems were tested in the surface temperature range of $1200-1450{ }^{\circ} \mathrm{C}$. The heating and cooling time periods were $5 \mathrm{~min}$ and $2 \mathrm{~min}$. The results indicated that the single-layer coating had a rather poor thermal cycling performance. The double-layer system showed a similar to or slightly better performance than that of YSZ coatings at temperatures below $1300^{\circ} \mathrm{C}$, suggesting the double-layer coating with $\mathrm{YSZ}$ is an effective way to improve the lifetime of TBC in thermal cycling tests [62]. Meanwhile, Cao et al. also showed that the single-layer LZ coating had a short thermal cycling lifetime, but the double-layer $\mathrm{LZ}$ coating with $\mathrm{La}_{2} \mathrm{O}_{3}-\mathrm{ZrO}_{2}-\mathrm{CeO}_{2}$ composite sublayer can greatly improve the lifetime [63]. However, the more layers that the TBC coating has, the more artificial defects might be generated during the deposition process. To reduce artificial defects, the composition, thickness and porosity in the double-layer coatings need to be properly tailored.

Bobzin et al. investigated the thermal cycling performance of EB-PVD deposited LZ and $7 \mathrm{YSZ}$ coatings using the FCT test [61]. The samples were heated to $1050{ }^{\circ} \mathrm{C}$ for about $30 \mathrm{~min}$, 
then cooled to $35^{\circ} \mathrm{C}$ in compressed air for $5 \mathrm{~min}$. Delamination of the $\mathrm{LZ}$ coating occurred at 1856 cycles, which showed a better performance than 7YSZ coating (1380 cycles). The alumina scale was observed in Bobzin's thermal cycle experiments, which was evidence of bond coat oxidation. Bobzin suggested that the main reason of the failure was a combined effect of oxidation of the bond coat and CTE mismatch. Guo et al. conducted JETS test for single-layer LZ coating and double-layer coating composed of LZ and 8YSZ deposited by APS with different porosities [45]. The front surfaces of the TBC samples were heated to $1232{ }^{\circ} \mathrm{C}$ for $20 \mathrm{~s}$, cooled by compressed $\mathrm{N}_{2}$ gas for $20 \mathrm{~s}$ and followed by ambient cooling for $40 \mathrm{~s}$. The front and back side temperatures were monitored during the test by pyrometers to analyze the cross-sectional temperature gradient. The initial spallation time of the TBC can be pinpointed by the temperature difference between the front and back side surfaces. Guo et al. showed that the single-layer porous 8YSZ coating had better JETS performance than the single-layer porous LZ coating. Additionally, Guo et al. showed that the thermal durability of LZ based coating can be improved by introducing a porous 8 YSZ buffer layer between the top and bond coat [45].

\subsection{Erosion test}

Erosion is regarded as a secondary cause of TBC failure by deteriorating the coating through progressive removal of the coating material, due to the mechanical interaction between coating surface and impinging solid particles [64]. The erosion tests by solid particle impingement were standardized by ASTM G76-13 [65]. Typically, $\mathrm{Al}_{2} \mathrm{O}_{3}$ medium with a particle size of $50 \mu \mathrm{m}$ is used as the abrasive particles, and the abrasive particles are accelerated by the high-velocity carrier gas through a particle-gas supply system. Finally, the abrasive particles are impacted on the surface of the coating at a specific impinging angle. The average erosion rate $(\mathrm{mg} / \mathrm{g}$ or $\mathrm{g} / \mathrm{kg})$ is used to evaluate the erosion resistance performance, which is determined by the slope of TBC mass loss (mg) versus the mass $(\mathrm{g})$ of erodent curve. Many variables like velocity, working distance, impact angle, abrasive particles properties, coating hardness and mechanical properties of coating ( $H$ and $\left.K_{I C}\right)$ can affect the erosion results. 
Erosion models of brittle materials such as the top coat in TBC can be described using the indentation theory of abrasive particles, which focuses on the relationship between TBC's material properties (e.g., $E$ and $K_{I C}$ ) and the erosion process conditions (e.g., impact velocity and abrasive particle size) [66-69]. It is necessary to determine whether an impinging particle will initiate cracks in the target material. The velocity threshold is used to express the critical condition to initiate the crack. Wellman proposed that the critical velocity of the abrasive particles to initiate fracture can be given by [70]:

$$
V_{c r i t}=105 \frac{E^{3 / 4} K_{I C}^{3}}{H^{13 / 4} \rho^{1 / 2} R^{3 / 2}}
$$

where $E$ is Young's modulus, $H$ is hardness, $K_{I C}$ is fracture toughness, $\rho$ is the density of the abrasive particles and $R$ is the particle radius. Since LZ has a lower $K_{I C}$ than 8 YSZ, low erosion resistance of $\mathrm{LZ}$ in the erosion test is expected [71].

Ramachandran et al. studied the erosion of APS deposited YSZ and LZ coatings with different coating porosities, abrasive particle velocities, and impact angles [72]. They found that the porosity level is the most predominant factor affecting the erosion rate of the coatings. High porosity in the coating increased erosion rate. The erosion rate increased with the increasing of the abrasive particles' velocity, which is consistent with Wellman's model in Equation 1. In addition, Ramachandran et al. found that LZ based coatings exhibited a better erosion resistance than the YSZ coatings, which was different from the theoretical expectation using Wellman's model.

One method to improve the erosion resistance is to use microstructure modification. For instance, columnar microstructure of EB-PVD deposited coating typically provides improvement of erosive resistance compared to the "splat" grain microstructure of APS deposited coating [64]. In addition, aging of APS coating decreases the erosion rate and therefore enhances the erosion performance. However, the aging of EB-PVD coating results in a significant increase of erosion rate due to the sintering of columns [64].

\subsection{Hot corrosion and CMAS infiltration damage}

During operation of a gas turbine engine, turbine ingests the intake air with various airborne chemical substances which will be burned with the fuel and air. The operation 
environment is filled with fuel, oxidized gasses and synthesized corrosive substances, which may deteriorate the coatings and substrates, so the chemical stability is important for TBCs. The most typical corrosive chemicals for TBCs in a gas turbine engine include vanadium compounds $\left(\mathrm{V}_{2} \mathrm{O}_{5}, \mathrm{NaVO}_{3}\right)$, sulfur-containing compounds $\left(\mathrm{SO}_{2}\right.$ and sulfate salts such as $\mathrm{Na}_{2} \mathrm{SO}_{4}, \mathrm{MgSO}_{4}$ ), and the mixture of them $[73,74]$. When the APS deposited LZ based TBC was exposed to the single corrosive chemical at high temperature, it was less damaged by the vanadium compounds (at $1000^{\circ} \mathrm{C}$ ) but severely attacked by the sulfur-containing compounds (at $900{ }^{\circ} \mathrm{C}$ ). However, the performance of the APS deposited 8YSZ based TBC in the same test was just the opposite situation. In the vanadia environment, many micro-cracks were generated in the $8 Y S Z$ coating, and spallation occurred finally. However, the $8 Y S Z$ coating showed an excellent resistance to sulfur-containing compounds [73]. In expecting to improve the corrosive resistance from $\mathrm{Na}_{2} \mathrm{SO}_{4}$ and $\mathrm{V}_{2} \mathrm{O}_{5}$, the $\mathrm{LZ}$ coating was deposited using EB-PVD with the addition of $\mathrm{Y}_{2} \mathrm{O}_{3}$ [74]. The composited coating exhibited a good resistance to $\mathrm{V}_{2} \mathrm{O}_{5}$ but experienced severe damage in the mixture of $\mathrm{Na}_{2} \mathrm{SO}_{4}+\mathrm{V}_{2} \mathrm{O}_{5}$. Xu et al. indicated that the excess of $\mathrm{La}_{2} \mathrm{O}_{3}$ in the composited coating can aggravate the corrosion by $\mathrm{Na}_{2} \mathrm{SO}_{4}$ and $\mathrm{V}_{2} \mathrm{O}_{5}$ [74].

The degradation of TBC by molten calcium-magnesium-alumino-silicates (CMAS) and volcanic ash infiltration have been concerned since TBC was introduced in gas turbines [75, 76]. CMAS attack primarily affects high-performance jet engines on account of their higher maximum temperatures and electricity-generation engines in some locations, but it will likely affect more engines as operation temperatures are increased in pursuit of greater engine efficiencies [77]. In the case of land-based electricity-generation engines, it is not always practical to filter out the finest particles that can be carried along with the input air and from alternative fuels such as syngas [77]. CMAS debris and the volcanic ashes are usually ingested with the intake air and deposited on TBCs. At elevated temperatures, the debris becomes liquid and penetrates the open void space in the coating. During the cooling process, it solidifies and reduces the strain tolerance of the coating [78]. When CMAS infiltration occurs in TBCs, a thermal shock delamination mechanism is easily activated [76]. Drexler et al. showed that TBCs with a good resistance against the CMAS must have a vigorously interaction with the molten CMAS, which result in rapid crystallization of the refractory oxide phase that form a sealing layer, stopping further penetration of the molten CMAS [79]. Rare 
earth pyrochlore materials, such as $\mathrm{Ga}_{2} \mathrm{Zr}_{2} \mathrm{O}_{7}$ and $\mathrm{La}_{2} \mathrm{Zr}_{2} \mathrm{O}_{7}$ were found to be highly effective in resisting high-temperature penetration of the molten CMAS debris and volcanic ash for prolonged durations[80-83]. This resistance is attributed to the formation of a sealing layer made of crystalline Ca-apatite phase $\left(\mathrm{Ca}_{2} \mathrm{Gd}_{8}\left(\mathrm{SiO}_{4}\right)_{6} \mathrm{O}_{2}\right.$ and $\left.\mathrm{Ca}_{2} \mathrm{La}_{8}\left(\mathrm{SiO}_{4}\right)_{6} \mathrm{O}_{2}\right)$ which prevents further infiltration of the liquid CMAS into the $\mathrm{TBC}[80,83]$. The CMAS resistance mechanism works for both APS and EB-PVD $\mathrm{La}_{2} \mathrm{Zr}_{2} \mathrm{O}_{7}$ coatings. Comparing to $\mathrm{La}_{2} \mathrm{Zr}_{2} \mathrm{O}_{7}$, YSZ coating is easily to be deteriorated by CMAS owing to (1) CMAS' potential for destabilization of the metastable tetragonal phase ( $t^{\prime}-$ YSZ), and (2) CMAS' penetration through the cracks of APS coating and the inter-columnar gaps of EB-PVD coating and reach far away to the TGO layer[75]. Because YSZ coating is lack of rapid formation of the crystalline products, it is vulnerable to CMAS attack or volcanic ash[83].

\section{Modeling and simulation}

\subsection{Thermal property calculations}

Material properties, including the physical, thermal and mechanical properties, can be calculated using modeling methods, such as first principles calculations, molecular dynamics (MD) method, finite element (FE) method, etc.

Feng et al. calculated the CTEs for $\mathrm{Ln}_{2} \mathrm{Zr}_{2} \mathrm{O}_{7}(\mathrm{Ln}=\mathrm{La}, \mathrm{Nd}, \mathrm{Sm}$, and $\mathrm{Gd})$ using the first principles calculations, as shown in Fig. 10 [54]. The quasi-harmonic approximation (QHA), Debye approximation and density functional theory (DFT) were employed in Feng's work to calculate the CTE as a function of temperature. The CTE $(\alpha, \beta)$ can be calculated using [54]:

$$
C_{p}-C_{v}=\beta^{2} V(T) B_{0}
$$

where $C_{p}$ and $C_{v}$ are the specific heats at constant pressure and volume, respectively; $\beta$ is the volumetric CTEs, $\beta=3 \alpha ; \alpha$ is the linear CTEs, $T$ is the temperature, and $B_{0}$ is the isothermal bulk modulus. The calculated CTE results showed good agreement with other researcher's experimental data [54]. Guo et al. investigated the $C_{p}$ of LZ single crystal using the first principles calculations, as shown in Fig. 8 [48]. 
The MD method can be used to investigate the thermal conductivity. For single crystals, there are two common molecular dynamics methods for thermal conductivity calculations, i.e., direct method $[84,85]$ and Green-Kubo method [86, 87]. The direct method is a nonequilibrium molecular dynamics (NEMD) method which imposes a temperature gradient to the system. The Green-Kubo method is an equilibrium MD (EMD) method which uses the current fluctuation to calculate the thermal conductivity according to the fluctuationdissipation theorem [88]. Schelling et al. predicted the thermal conductivities of several dozens of single crystal pyrochlores with the composition of $\mathrm{A}_{2} \mathrm{~B}_{2} \mathrm{O}_{7}$ ( $\mathrm{A}$ is a rare earth element, and $\mathrm{B}=\mathrm{Ti}, \mathrm{Mo}, \mathrm{Sn}, \mathrm{Zr}$ or $\mathrm{Pb}$ ) using the NEMD methods with Buckingham potentials [84]. The calculated thermal conductivity of single crystal LZ was $1.98 \mathrm{~W} / \mathrm{m} / \mathrm{K}$ at $1200{ }^{\circ} \mathrm{C}$ [84]. A more reliable method to compute thermal conductivity is the reverse NEMD (RNEMD) method [89]. In RNEMD method, the Muller-Plathe algorithm [90] is used to exchange kinetic energy between two atoms in different regions of the simulation box at every finite step to induce a temperature gradient in the system. It works by exchanging velocities between two atoms in different parts of the simulation cell. At set intervals, the velocity of the fastest atom in one region is replaced by the velocity of the slowest atom in another region and vice versa. Consequently, the first region becomes colder, whereas, the second region increases in temperature. The system will be reacted by flowing energy from the hot to cold regions. Eventually, a steady state is established when the exchanged energy equilibrates the energy flowing back in a temperature gradient over the space between. The usual NEMD approach is to impose a temperature gradient on the system and measure the response as the resulting heat flux. In RNEMD using the Muller-Plathe algorithm, the heat flux is imposed, and the temperature gradient is the system's response. The advantage of NEMD over traditional NEMD is that there are no artificial "temperature walls" in the simulated system, since these cause a fluid structure different from the bulk. Additionally, energy and momentum are conserved, and there are no thermostat issues [89].

Chartier calculated the $C_{p}$ of LZ using molecular dynamic (MD), as shown in Fig. 8 [49]. The Buckingham and Coulomb force field was used to describe the interaction between each atom. As shown in Fig. 8, the predicted $C_{p}$ values were very close to the experiments result. Schelling et al. investigated the thermal conductivity of pyrochlores with the composition of $\mathrm{A}_{2} \mathrm{~B}_{2} \mathrm{O}_{7}(\mathrm{~A}=\mathrm{La}, \mathrm{Pr}, \mathrm{Nd}, \mathrm{Sm}, \mathrm{Eu}, \mathrm{Gd}, \mathrm{Y}, \mathrm{Er}$ or Lu; B=Ti, Mo, Sn, Zr or Pb) using molecular 
dynamics method at $1200{ }^{\circ} \mathrm{C}$ [84]. The results showed that the thermal conductivities did not show a strong dependence on ionic radius of $\mathrm{A}$, but tended to decrease with increasing ionic radius of B, as shown in Fig. 11 [84].

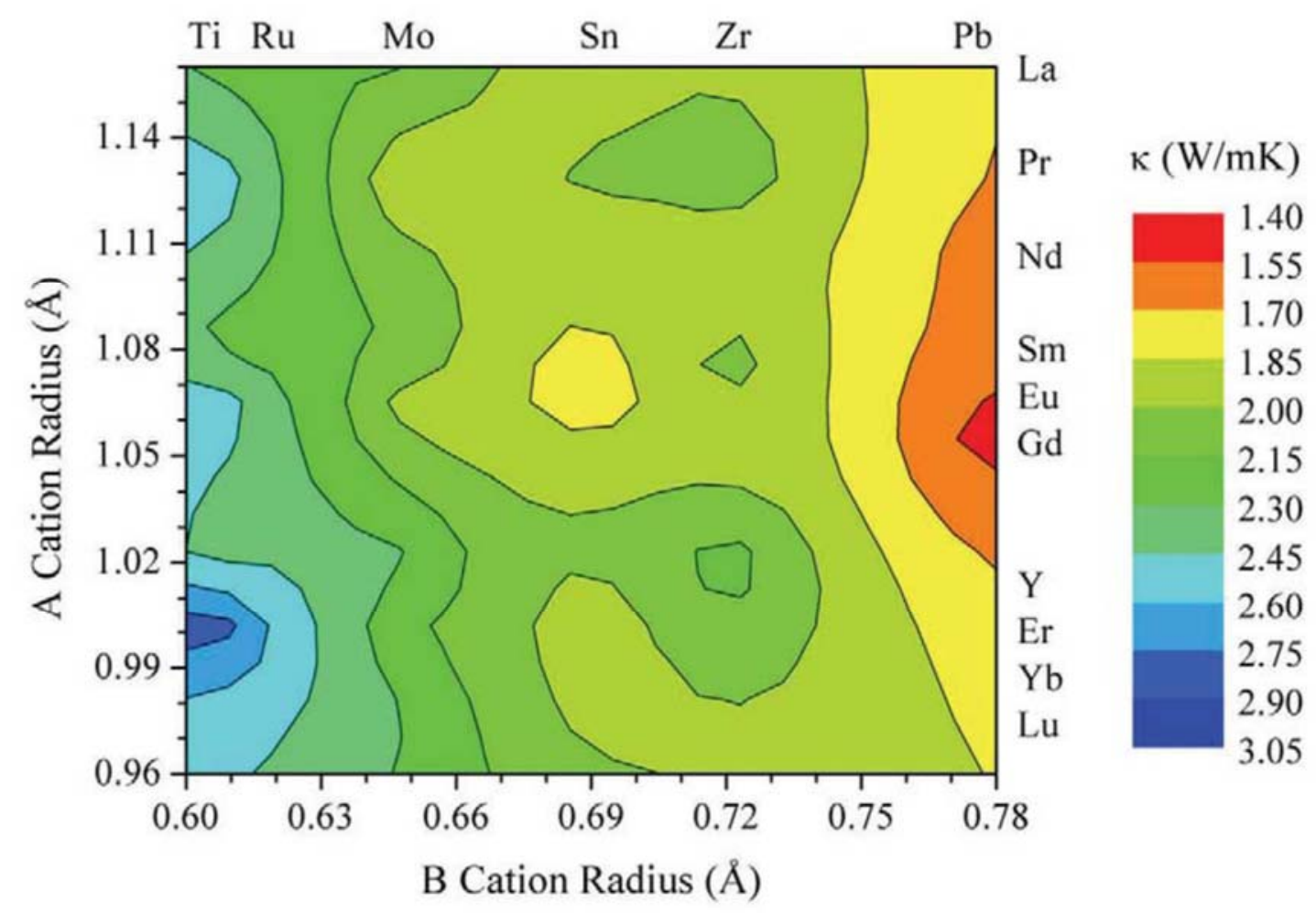

Fig. 11: Contour map of thermal conductivity of $\mathrm{A}_{2} \mathrm{~B}_{2} \mathrm{O}_{7}$ as a function of radii of $\mathrm{A}$ and $\mathrm{B}$ ions [84].

The FE method has been used to simulate heat conduction process of coating structures with cracks and pores [91]. In addition, the quantitative imaging analysis method can be used to investigate the non-uniformity properties of the porous coating with polycrystalline microstructure $[26,40]$. The pore and crack morphology of TBC is an important parameter affecting the mechanical and thermal properties $[92,93]$. The thermal properties of nonuniform porous polycrystalline coatings can be calculated using image based FE method. Image based FE method uses scanning electron microscope (SEM) images to generate microstructures and import into the FE model [94].

Arai et al. studied the thermal conductivities of TBCs with different porosities using SEMimage-based FE modeling [93]. They found that the presence of the pores disturbed the heat 
transfer in their models. In addition, the thermal conductivity of plasma sprayed porous YSZ was investigated by many researchers using FE method [95, 96]. The calculated effective thermal conductivities were in good agreement with experimental results. Guo et al. predicted the thermal conductivity of porous LZ coatings using an image based multi-scale simulation method, which combined the MD and FE calculations[51]. The reverse non-equilibrium molecular dynamics approach was used in Guo's work to compute the temperature-dependent thermal conductivity of single crystal LZ. The single crystal thermal conductivity values were then passed to the FE model which was generated from the SEM images of the LZ coating with a porosity of $10.0 \% \sim 12.3 \%$. The predicted thermal conductivities from the FE model are shown in Fig. 9. The imaged based FE calculated thermal conductivity data are slightly lower than the experiments data. The deviation might come from the artificial errors during the SEM image conversion and the FE mesh process. The limitation of this image based FE model is that SEM images can't fully reflect the coating microstructure in 3-dimensional space. The model converted from the SEM images might miss some microstructure details, which leads to the deviation of the thermal conductivity results.

\subsection{Mechanical property calculations}

Similar to aforementioned thermal properties, the mechanical properties of LZ crystal can also be predicted using various modeling techniques.

The elastic constants of a material describe its response to an applied stress or, conversely, the stress required to maintain a given deformation. Elastic properties such as Young' modulus, bulk modulus, shear modulus and Poisson's ratio can be analytically calculated from the elastic constants [97]. Liu et al. calculated the elastic constants of LZ using the first principles calculations [98]. From the results of elastic constants, Liu calculated the anisotropic $E$ values on (011) plane. The maximum Young's modulus was $225 \mathrm{GPa}$, which was along $<111>$ direction. The minimum Young's modulus was $214 \mathrm{GPa}$, which was along $<100>$ direction [98]. Feng et al. investigated the hardness and elastic modulus using localdensity approximation of spin polarized scheme (LDA+U, U is Hubbard energy) [99]. The calculated bulk modulus was $176 \mathrm{GPa}$, Young's modulus was $208 \mathrm{GPa}$, shear modulus was $87 \mathrm{GPa}$, Poisson's ratio was 0.302 , and the calculated hardness was $8.9 \mathrm{GPa}$. The theoretically 
calculated results are in good agreement with experimental results, which are listed in Table 2. Again, there are some deviations between the modeling and the experimental results, because the models used in the above calculations are for perfect crystal. The actual samples contains grain boundaries or defects.

\subsection{Gas adsorption and oxidation modeling}

Complementing to experimental effort, modeling technique provides an alternative way to interpret gas adsorption and oxidation process. Oxidizing gas adsorption on TBC surface is the first step of the oxidation process. The surface energies on (001), (011) and (111) planes in LZ need to be calculated, before the calculated the gas adsorption. Guo et al. studied the $\mathrm{CO}_{2}$ and $\mathrm{O}_{2}$ molecule adsorption on the surface of LZ using the DFT method $[100,101]$. The (011) plane was the most thermodynamically stable planes in LZ crystal. The plane with the lowest adsorption energy was regarded as the most favorable gas adsorption plane.

Oxygen migration in TBCs results in the oxidation of the bond coat to form the TGO layer, which may protect the bond coat from rapid oxidation if a slow growing alpha alumina scale is formed. However, if the oxygen migration continues, the TGO layer grows thicker. This can also lead to the delamination of TBCs due to crack generations in thick TGO layer. Pirzada et al. predicted the activation energies for the oxygen migration using the atomic scale simulation [102]. In this model, the oxygen migration proceeded through an oxygen vacancy mechanism with the oxygen ions hopping between $48 \mathrm{f}$ sites and the unoccupied $8 \mathrm{a}$ interstitial position played an important role in the migration mechanism. The oxygen migration activation energy was calculated for a series of $\mathrm{A}_{2} \mathrm{~B}_{2} \mathrm{O}_{7}$ materials $(\mathrm{A}=\mathrm{La}, \mathrm{Pr}, \mathrm{Nd}, \mathrm{Sm}, \mathrm{Eu}, \mathrm{Gd}$, $\mathrm{Y}, \mathrm{Er}, \mathrm{Yb}, \mathrm{Lu}$ and $\mathrm{B}=\mathrm{Ti}, \mathrm{Ru}, \mathrm{Mo}, \mathrm{Sn}, \mathrm{Zr}, \mathrm{Pb})$, as shown in Fig. 12 [102]. The results suggest that the activation energies may not be strictly related to the radii of the A and B cations. LZ crystal exhibits a higher activation energy for oxygen migration than other zirconate pyrochlore compounds containing rare earth elements which may minimize the chance of oxidation failure in TBCs. 


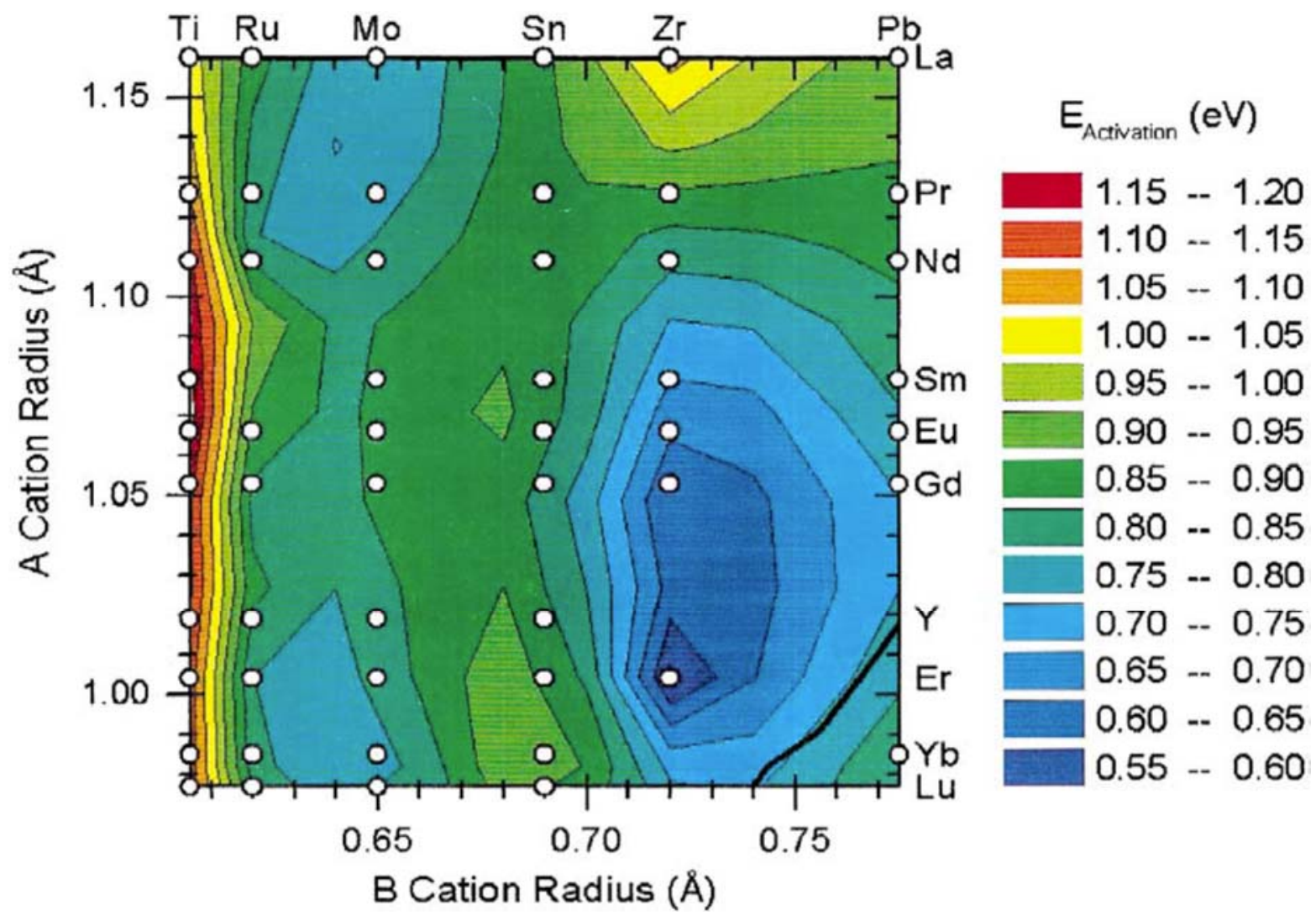

Fig. 12: Oxygen migration activation energy of $\mathrm{A}_{2} \mathrm{~B}_{2} \mathrm{O}_{7}$ materials as a function of radii of $\mathrm{A}$ and $\mathrm{B}$ cations [102]

\section{Concluding remarks on future research directions}

In this paper, lanthanum zirconate material and its application as thermal barrier coating are comprehensively reviewed. The coating deposition technique, the physical, thermal, mechanical, and thermal durability of the coatings are summarized. In general, LZ coatings have much better thermal and phase stability than 8 YSZ coatings. The hardness of LZ coating is slightly lower than that of $8 \mathrm{YSZ}$, and the fracture toughness is much lower than that of 8YSZ. Since TBC is a quite complicated composite material system, there are many factors related to the TBCs properties and durability, the research on LZ based TBC is still far from the end. Based on this review, the following research directions are identified for $\mathrm{LZ}$ to be used as promising TBC materials.

(1) LZ coating has a lower fracture toughness than 8YSZ, as shown in Table 2. The low fracture toughness leads to cracking at modest stress levels. It becomes very important to 
improve the fracture toughness of LZ based coatings. Strategies include composite coating or multi-layer gradient coating architectures, which have demonstrated improved durability performance in thermal cycling test. The exact composite or multi-layer structures need to be optimized since artificial defects may be introduced at the interface. Another strategy could be using doping of LZ, which shows increased fracture toughness. Again, the selections of doping elements and the doping ratio are still unclear, which requires further investigation.

(2) The coefficient of thermal expansion of LZ needs to be increased to minimize residual stress at the interface between the top and bond or substrate. Using doping with selected elements, coefficient of thermal expansion can be slightly increased. However, a material that has better thermal properties does not guarantee a good thermal cycling performance. Thermal durability experiments of low thermal conductivity materials need to be conducted to simulate gas turbine operating conditions.

(3) Further studies of hot corrosion and CMAS resistance of LZ material are needed, as the operating environments of advanced gas turbines contains multiple chemicals and substances, which will affect the chemical stability at extreme conditions.

(4) Failure mechanisms of LZ coatings in combined thermal, mechanical, and chemical environment are totally unclear. The integration of experimental techniques and theoretical modeling tools can be the most powerful way to unfold the mystery of failures in the LZ based TBCs. The modeling studies of interfacial failure, TGO initiation and growth, bond coating oxidation and cracking in LZ coating are still challenging, which are needed to fully understand failure mechanisms and improve the design of future advanced TBC coatings.

\section{Acknowledgments}

Jing Zhang acknowledges the financial support provided by the United States Department of Energy (Grant No. DE-FE0008868, program manager: Richard Dunst) and IUPUI RSFG 
and IDRF grants. Jing Zhang thanks Yang Ren at Argonne National Laboratory for generating the synchrotron XRD data shown in Fig. 4, through using the resources of the Advanced Photon Source, a U.S. Department of Energy (DOE) Office of Science User Facility operated for the DOE Office of Science by Argonne National Laboratory under Contract No. DEAC02-06CH11357. Yeon-Gil Jung acknowledges the financial support provided by the National Research Foundation of Korea (NRF) Grant funded by the Korean Government (MEST) (2011-0030058), by the Power Generation \& Electricity Delivery of the Korea Institute of Energy Technology Evaluation and Planning (KETEP) Grants funded by the Korea Ministry of Knowledge Economy (2013-101010-170C). The authors also thank the critical comments from the anonymous reviewers. 


\section{References}

1. Clarke, D.R., M. Oechsner, and N.P. Padture, Thermal-barrier coatings for more efficient gas-turbine engines. MRS Bulletin, 2012. 37(10): p. 891-898.

2. Clarke, D. and C. Levi, Materials design for the next generation thermal barrier coatings. Annual Review of Materials Research, 2003. 33(1): p. 383-417.

3. Weber, S.B., et al., Lanthanum zirconate thermal barrier coatings deposited by spray pyrolysis. Surface and Coatings Technology, 2013. 227(0): p. 10-14.

4. Taylor, T.A., Low thermal expansion bondcoats for thermal barrier coatings. 2011, US Patents No.7910225 B2.

5. Davis, J.R., Handbook of thermal spray technology. 2004: ASM international.

6. Nelson, W.A. and R.M. Orenstein, TBC experience in land-based gas turbines. Journal of Thermal Spray Technology, 1997. 6(2): p. 176-180.

7. Fauchais, P.L., J.V. Heberlein, and M. Boulos, Thermal spray fundamentals: From powder to part. 2014: Springer Science \& Business Media.

8. Chen, M., et al., Characterization and modeling of a martensitic transformation in a platinum modified diffusion aluminide bond coat for thermal barrier coatings. Acta Materialia, 2003. 51(14): p. 4279-4294.

9. Padture, N.P., M. Gell, and E.H. Jordan, Thermal Barrier Coatings for Gas-Turbine Engine Applications. Science, 2002. 296(5566): p. 280-284.

10. Vassen, R., et al., Zirconates as New Materials for Thermal Barrier Coatings. Journal of the American Ceramic Society, 2000. 83(8): p. 2023-2028.

11. Schlichting, K.W., N.P. Padture, and P.G. Klemens, Thermal conductivity of dense and porous yttria-stabilized zirconia. Journal of Materials Science, 2001. 36(12): p. 3003-3010.

12. Hasselman, D.P.H., et al., Thermal diffusivity and conductivity of dense polycrystalline $\mathrm{ZrO}_{2}$ ceramics: a survey. American Ceramic Society Bulletin, 1987. 66(5): p. 799-806.

13. Cao, X.Q., et al., Thermal Stability of Lanthanum Zirconate Plasma-Sprayed Coating. Journal of the American Ceramic Society, 2001. 84(9): p. 2086-2090.

14. Lu, Z., et al., Thermal stability and mechanical properties of thick thermal barrier coatings with vertical type cracks. Transactions of Nonferrous Metals Society of China, 2014. 24, Supplement 1(0): p. s29-s35.

15. Subramanian, M.A., G. Aravamudan, and G.V. Subba Rao, Oxide pyrochlores - A review. Progress in Solid State Chemistry, 1983. 15(2): p. 55-143.

16. Bolech, M., et al., The heat capacity and derived thermodynamic functions of $\mathrm{La}_{2} \mathrm{Zr}_{2} \mathrm{O}_{7}$ and $\mathrm{Ce}_{2} \mathrm{Zr}_{2} \mathrm{O}_{7}$ from 4 to $1000 \mathrm{~K}$. Journal of Physics and Chemistry of Solids, 1997. 58(3): p. 433-439.

17. D. Sedmidubsky, O.Benes, and R.J.M. Konings, High temperature heat capacity of $\mathrm{Nd}_{2} \mathrm{Zr}_{2} \mathrm{O}_{7}$ and $\mathrm{La}_{2} \mathrm{Zr}_{2} \mathrm{O}_{7}$ pyrochlores. J. chem. Thermodynamics, 2005. 37: p. 10981103.

18. Shimamura, K., et al., Thermophysical Properties of Rare-Earth-Stabilized Zirconia and Zirconate Pyrochlores as Surrogates for Actinide-Doped Zirconia. International Journal of Thermophysics, 2007. 28(3): p. 1074-1084. 
19. Moriga, T., et al., Crystal structure analyses of the pyrochlore and fluorite-type Zr2Gd2O7 and anti-phase domain structure. Solid State Ionics, 1989. 31(4): p. 319328.

20. Michel, D., M.P. y Jorba, and R. Collongues, Study by Raman spectroscopy of orderdisorder phenomena occurring in some binary oxides with fluorite-related structures. Journal of Raman Spectroscopy, 1976. 5(2): p. 163-180.

21. Tabira, Y., et al., Systematic Structural Change in Selected Rare Earth Oxide Pyrochlores as Determined by Wide-Angle CBED and a Comparison with the Results of Atomistic Computer Simulation. Journal of Solid State Chemistry, 2000. 153(1): p. 16-25.

22. Brown, F.H. and P.O.L. Duwez, The Systems Zirconia-Lanthana and ZirconiaNeodymia. Journal of the American Ceramic Society, 1955. 38(3): p. 95-101.

23. Roth, R.S., Pyrochlore-type compounds containing double oxides of trivalent and tetravalent ions. Journal of Research of the National Bureau of Standards, 1956. 56(1): p. 17-25.

24. Maloney, M.J., Thermal barrier coating systems and materials. 2000, US Patents No. $6,117,560$.

25. Zhang, J., Novel Functional Graded Thermal Barrier Coatings in Coal-fired Power Plant Turbines. 2015 NETL Crossingcutting Research Review Meeting, Pittsburgh, PA, April 27-30, 2015, 2015.

26. Zhang, J., et al., Microstructural non-uniformity and mechanical property of air plasma-sprayed dense lanthanum zirconate thermal barrier coating. Materials Today: Proceedings, 2014. 1(1): p. 11-16.

27. Zhang, J., et al. Quantitative Analysis of Pore Morphology in Lanthanum Zirconate Thermal Barrier Coating. in Materials Science \& Technology 2014 (MS\&T). 2014. $2061-2068$.

28. Di Girolamo, G., et al., Evolution of microstructural and mechanical properties of lanthanum zirconate thermal barrier coatings at high temperature. Surface and Coatings Technology, 2015. 268: p. 298-302.

29. $\mathrm{Xu}, \mathrm{Z}$., et al., Double -Ceramic-layer $\mathrm{TBC}$ of $\mathrm{La}_{2} \mathrm{Zr}_{2} \mathrm{O}_{7} / \mathrm{YSZ}$ deposited by electron beam-physical vapor deposition. Journal of Alloys and Compounds, 2009. 473: p. 509-515.

30. Saruhan, B., et al., EB-PVD processing of pyrochlore-structured La2Zr2O7-based TBCs. Surface and Coatings Technology, 2004. 182(2-3): p. 175-183.

31. Bobzin, K., et al., Influence of temperature on phase stability and thermal conductivity of single- and double-ceramic-layer EB-PVD TBC top coats consisting of 7YSZ, $\mathrm{Gd}_{2} \mathrm{Zr}_{2} \mathrm{O}_{7}$ and $\mathrm{La}_{2} \mathrm{Zr}_{2} \mathrm{O}_{7}$. Surface and Coatings Technology, 2013. 237(0): p. 56-64.

32. Wang, C., et al., Nanocomposite Lanthanum Zirconate Thermal Barrier Coating Deposited by Suspension Plasma Spray Process. Journal of Thermal Spray Technology, 2014. 23(7): p. 1030-1036.

33. Weber, S.B., et al., Deposition mechanisms of thick lanthanum zirconate coatings by spray pyrolysis. Journal of the American Ceramic Society, 2011.94(12): p. 4256-4262.

34. Lehmann, H., et al., Thermal Conductivity and Thermal Expansion Coefficients of the Lanthanum Rare-Earth-Element Zirconate System. Journal of the American Ceramic Society, 2003. 86(8): p. 1338-1344. 
35. Standard Test Method for Density, Oil Content, and Interconnected Porosity of Sintered Metal Structural Parts and Oil-Impregnated Bearings, in ASTM standard 328-96. 1996, American Society of Testing and Materials: West Conshohocken, PA.

36. Myoung, S.-W., et al., Microstructure design and mechanical properties of thermal barrier coatings with layered top and bond coats. Surface and Coatings Technology, 2010. 205(5): p. 1229-1235.

37. Vassen, R., et al. La2Zr2O7-a new candidate for thermal barrier coatings. in Proceedings of the United Thermal Spray Conference-UTSC'99. 1999. DVS-Verlag, Düsseldorf, Germany.

38. Zhu, D., N.P. Bansal, and R.A. Miller. Thermal Conductivity and Stability of HfO2Y2O3 and La2Zr2O7 Evaluated for 1650 C Thermal/Environmental Barrier Coating Applications. in Proceedings of the 105th Annual Meeting and Exposition of the American Ceramic Society, The American Ceramic Society, Nashville, TN. 2003.

39. Nair, J., et al., Sintering of lanthanum zirconate. Journal of the American Ceramic Society, 1999. 82(8): p. 2066-2072.

40. Jing Zhang, X.G., Yeon -Gil Jung, Li Li, James Knapp, Quantitative analysis of pore morphology in lanthanum zirconate thermal barrier coating. Materials Science and Technology (MS\&T) 2014, 2014: p. 2061-2068.

41. Weber, S.B., et al., Thermal and mechanical properties of crack-designed thick lanthanum zirconate coatings. Journal of the European Ceramic Society, 2014. 34(4): p. 975-984.

42. Hong, Q.-J., Methods for melting temperature calculation. 2015, California Institute of Technology.

43. Ushakov, S.V. and A. Navrotsky, Experimental approaches to the thermodynamics of ceramics above 1500 C. Journal of the American Ceramic Society, 2012. 95(5): $p$. 1463-1482.

44. Khor, K.A. and Y.W. Gu, Thermal properties of plasma-sprayed functionally graded thermal barrier coatings. Thin Solid Films, 2000. 372(1-2): p. 104-113.

45. Guo, X., et al., Thermal Properties, Thermal Shock, and Thermal Cycling Behavior of Lanthanum Zirconate-Based Thermal Barrier Coatings. Metallurgical and Materials Transactions E, 2016. 3(2): p. 64-70.

46. Chen, H., et al., Thermophysical properties of lanthanum zirconate coating prepared by plasma spraying and the influence of post-annealing. Journal of Alloys and Compounds, 2009. 486(1-2): p. 391-399.

47. Zhang, J., et al., Thermal expansion and solubility limits of cerium-doped lanthanum zirconates. Journal of Alloys and Compounds, 2012. 525(0): p. 78-81.

48. Guo, X. and J. Zhang, First Principles Study of Thermodynamic Properties of Lanthanum Zirconate. Materials Today: Proceedings, 2014. 1(1): p. 25-34.

49. Chartier, A., et al., Atomistic modeling of displacement cascades in $\mathrm{La}_{2} \mathrm{Zr}_{2} \mathrm{O}_{7}$ pyrochlore. Physical Review B, 2003. 67(17): p. 174102.

50. Bansal, N.P. and D. Zhu, Effects of doping on thermal conductivity of pyrochlore oxides for advanced thermal barrier coatings. Materials Science and Engineering: A, 2007. 459(1-2): p. 192-195.

51. Guo, X., et al., Image-based multi-scale simulation and experimental validation of thermal conductivity of lanthanum zirconate. International Journal of Heat and Mass Transfer, 2016. 100: p. 34-38. 
52. Wang, Y., The improvement of thermal and mechanical properties of $\mathrm{La}_{2} \mathrm{Zr}_{2} \mathrm{O}_{7}$-based pyrochlores as high temperature thermal barrier coatings, in PhD thesis, School of Materials. 2013, The University of Manchester: Manchester, UK.

53. Xiang, J., et al., Phase structure and thermophysical properties of co-doped La2Zr2O7 ceramics for thermal barrier coatings. Ceramics International, 2012. 38(5): p. 3607-3612.

54. Feng, J., et al., Thermal expansions of $\operatorname{Ln} 2 \mathrm{Zr} 2 \mathrm{O} 7$ ( $\mathrm{Ln}=\mathrm{La}, \mathrm{Nd}$, Sm, and $\mathrm{Gd}$ ) pyrochlore. Journal of Applied Physics, 2012. 111(10): p. 4.

55. Cao, X.Q., R. Vassen, and D. Stoever, Ceramic materials for thermal barrier coatings. Journal of the European Ceramic Society, 2004. 24(1): p. 1-10.

56. $\mathrm{Xu}, \mathrm{Z}$., et al., Preparation and characterization of La2Zr2O7 coating with the addition of Y2O3 by EB-PVD. Journal of Alloys and Compounds, 2010. 492(1-2): p. 701-705.

57. Beshish, G.K., et al., Fracture toughness of thermal spray ceramic coatings determined by the indentation technique. Journal of Thermal Spray Technology, 1993. 2(1): p. 35-38.

58. Jiang, K., et al., Microstructure and mechanical properties of La2Zr2O7(Zr0.92Y0.08)O1.96 composite ceramics prepared by spark plasma sintering. Ceramics International, 2014. 40(9, Part A): p. 13979-13985.

59. Vaßen, R., et al., Testing and evaluation of thermal-barrier coatings. MRS Bulletin, 2012. 37(10): p. 911-916.

60. Bolcavage, A., et al., Thermal shock testing of thermal barrier coating/bondcoat systems. Journal of Materials Engineering and Performance, 2004. 13(4): p. 389-397.

61. Bobzin, K., E. Lugscheider, and N. Bagcivan, Thermal Cycling Behaviour of Lanthanum Zirconate as EB-PVD Thermal Barrier Coating. Advanced Engineering Materials, 2006. 8(7): p. 653-657.

62. Vaßen, R., F. Traeger, and D. Stöver, New Thermal Barrier Coatings Based on Pyrochlore/YSZ Double-Layer Systems. International Journal of Applied Ceramic Technology, 2004. 1(4): p. 351-361.

63. Wang, L., et al., Thermal shock behavior of 8YSZ and double-ceramic-layer La2Zr2O7/8YSZ thermal barrier coatings fabricated by atmospheric plasma spraying. Ceramics International, 2012. 38(5): p. 3595-3606.

64. Wellman, R. and J. Nicholls, A review of the erosion of thermal barrier coatings. Journal of Physics D: Applied Physics, 2007. 40(16): p. R293.

65. Standard Test Method for Conducting Erosion Tests by Solid Particle Impingement Using Gas Jets, in ASTM G76-13. 2015, American Society of Testing and Materials: West Conshohocken, PA.

66. Marshall, D.B., B.R. Lawn, and A.G. Evans, Elastic/Plastic Indentation Damage in Ceramics: The Lateral Crack System. Journal of the American Ceramic Society, 1982. 65(11): p. 561-566.

67. Park, D., M.-W. Cho, and H. Lee, Effects of the impact angle variations on the erosion rate of glass in powder blasting process. The International Journal of Advanced Manufacturing Technology, 2004. 23(5-6): p. 444-450.

68. Verma, A.P. and G.K. Lal, A Theoretical Study of Erosion Phenomenon in Abrasive Jet Machining. Journal of Manufacturing Science and Engineering, 1996. 118(4): p. 564. 
69. Slikkerveer, P.J., et al., Erosion and damage by sharp particles. Wear, 1998. 217(2): p. 237-250.

70. Wellman, R.G. and J.R. Nicholls, A Monte Carlo model for predicting the erosion rate of EB PVD TBCs. Wear, 2004. 256(9-10): p. 889-899.

71. Schmitt, M.P., B.J. Harder, and D.E. Wolfe, Process-structure-property relations for the erosion durability of plasma spray-physical vapor deposition (PS-PVD) thermal barrier coatings. Surface and Coatings Technology, 2016. 297: p. 11-18.

72. Ramachandran, C.S., V. Balasubramanian, and P.V. Ananthapadmanabhan, Erosion of atmospheric plasma sprayed rare earth oxide coatings under air suspended corundum particles. Ceramics International, 2013. 39(1): p. 649-672.

73. Marple, B.R., et al., Hot Corrosion of Lanthanum Zirconate and Partially Stabilized Zirconia Thermal Barrier Coatings. Journal of Engineering for Gas Turbines and Power, 2006. 128(1): p. 144.

74. $\mathrm{Xu}, \mathrm{Z}$., et al., Hot corrosion behavior of $\mathrm{La}_{2} \mathrm{Zr}_{2} \mathrm{O}_{7}$ with the addition of $\mathrm{Y}_{2} \mathrm{O}_{3}$ thermal barrier coatings in contacts with vanadate-sulfate salts. Journal of Alloys and Compounds, 2010. 504: p. 382-385.

75. Levi, C.G., et al., Environmental degradation of thermal-barrier coatings by molten deposits. MRS bulletin, 2012. 37(10): p. 932-941.

76. Mercer, C., et al., A delamination mechanism for thermal barrier coatings subject to calcium-magnesium-alumino-silicate (CMAS) infiltration. Acta Materialia, 2005. 53(4): p. 1029-1039.

77. Clarke, D.R., M. Oechsner, and N.P. Padture, Thermal-barrier coatings for more efficient gas-turbine engines. MRS Bulletin, 2012. 37(10).

78. Vaßen, R., et al., Overview on advanced thermal barrier coatings. Surface and Coatings Technology, 2010. 205(4): p. 938-942.

79. Drexler, J.M., A.L. Ortiz, and N.P. Padture, Composition effects of thermal barrier coating ceramics on their interaction with molten $\mathrm{Ca}-\mathrm{Mg}-\mathrm{Al}$-silicate (CMAS) glass. Acta Materialia, 2012. 60(15): p. 5437-5447.

80. Drexler, J.M., et al., Plasma sprayed gadolinium zirconate thermal barrier coatings that are resistant to damage by molten $\mathrm{Ca}-\mathrm{Mg}-\mathrm{Al}-$ silicate glass. Surface and Coatings Technology, 2012. 206(19): p. 3911-3916.

81. Krämer, S., J. Yang, and C.G. Levi, Infiltration-Inhibiting Reaction of Gadolinium Zirconate Thermal Barrier Coatings with CMAS Melts. Journal of the American Ceramic Society, 2008. 91(2): p. 576-583.

82. Mechnich, P. and W. Braue, Volcanic Ash-Induced Decomposition of EB-PVD $\mathrm{Gd}_{2} \mathrm{Zr}_{2} \mathrm{O}_{7}$ Thermal Barrier Coatings to Gd-Oxyapatite, Zircon, and $\mathrm{Gd}$, FeZirconolite. Journal of the American Ceramic Society, 2013. 96(6): p. 1958-1965.

83. Schulz, U. and W. Braue, Degradation of $\mathrm{La}_{2} \mathrm{Zr}_{2} \mathrm{O}_{7}$ and other novel EB-PVD thermal barrier coatings by $\mathrm{CMAS}$ ( $\left.\mathrm{CaO}-\mathrm{MgO}-\mathrm{Al}_{2} \mathrm{O}_{3}-\mathrm{SiO}_{2}\right)$ and volcanic ash deposits. Surface and Coatings Technology, 2013. 235: p. 165-173.

84. Schelling, P.K., S.R. Phillpot, and R.W. Grimes, Optimum pyrochlore compositions for low thermal conductivity. Philosophical Magazine Letters, 2004. 84(2): p. 127-137.

85. Maiti, A., G.D. Mahan, and S.T. Pantelides, Dynamical simulations of nonequilibrium processes - Heat flow and the Kapitza resistance across grain boundaries. Solid State Communications, 1997. 102(7): p. 517-521. 
86. Kubo, R., Statistical Physics II Nonequilibrium Statistical Mechanics. Second edition.. ed, ed. M. Toda and N. Hashitsume. 1991, Berlin, Heidelberg: Berlin, Heidelberg : Springer Berlin Heidelberg.

87. Che, J., et al., Thermal conductivity of diamond and related materials from molecular dynamics simulations. The Journal of Chemical Physics, 2000. 113(16): p. 6888-6900.

88. Schelling, P.K., S.R. Phillpot, and P. Keblinski, Comparison of atomic-level simulation methods for computing thermal conductivity. Physical Review B, 2002. 65(14): p. 144306.

89. Müller-Plathe, F., A simple nonequilibrium molecular dynamics method for calculating the thermal conductivity. The Journal of Chemical Physics, 1997. 106(14): p. 6082-6085.

90. Müller-Plathe, F., Reversing the perturbation in nonequilibrium molecular dynamics: An easy way to calculate the shear viscosity of fluids. Physical Review E, 1999. 59(5): p. 4894-4898.

91. Wang, L., et al., Modeling of thermal properties and failure of thermal barrier coatings with the use of finite element methods: A review. Journal of the European Ceramic Society, 2016. 36(6): p. 1313-1331.

92. Wang, L., et al., Influence of pores on the surface microcompression mechanical response of thermal barrier coatings fabricated by atmospheric plasma spray-Finite element simulation. Applied Surface Science, 2011. 257(6): p. 2238-2249.

93. Arai, M., H. Ochiai, and T. Suidzu, A novel low-thermal-conductivity plasma-sprayed thermal barrier coating controlled by large pores. Surface and Coatings Technology, 2016. 285: p. 120-127.

94. Keyak, J.H., et al., Automated three-dimensional finite element modelling of bone: a new method. Journal of Biomedical Engineering, 1990. 12(5): p. 389-397.

95. Wang, Z., et al., Effects of pores and interfaces on effective properties of plasma sprayed zirconia coatings. Acta Materialia, 2003. 51(18): p. 5319-5334.

96. Wang, Y., et al., Melting index characterization and thermal conductivity model of plasma sprayed YSZ coatings. Journal of the European Ceramic Society, 2012. 32(14): p. 3701-3707.

97. Ingel, R.P. and D.L. Iii, Elastic Anisotropy in Zirconia Single Crystals. Journal of the American Ceramic Society, 1988. 71(4): p. 265-271.

98. Liu, B., et al., Theoretical elastic stiffness, structure stability and thermal conductivity of La2Zr2O7 pyrochlore. Acta Materialia, 2007. 55(9): p. 2949-2957.

99. Feng, J., et al., Electronic structure, mechanical properties and thermal conductivity of $\mathrm{Ln} 2 \mathrm{Zr} 2 \mathrm{O} 7$ (Ln\&\#xa0;=\&\#xa0;La, $\mathrm{Pr}, \mathrm{Nd}, \mathrm{Sm}, \mathrm{Eu}$ and $\mathrm{Gd}$ ) pyrochlore. Acta Materialia, 2011. 59(4): p. 1742-1760.

100. Guo, X., et al., Carbon dioxide adsorption on lanthanum zirconate nanostructured coating surface: a DFT study. Adsorption, 2015. 22(2): p. 159-163.

101. Guo, X., et al., First Principles study of nanoscale mechanism of oxygen adsorption on lanthanum Zirconate surfaces. Physica E: Low-dimensional Systems and Nanostructures, 2016. 83: p. 36-40.

102. Pirzada, M., et al., Oxygen migration in A2B2O7 pyrochlores. Solid State Ionics, 2001. 140(3-4): p. 201-208. 